FEE COPY

NBSIR $82-2542$

\title{
Micromechanical Properties of Beryllium and Other Instrument Materials
}

U.S. DEPARTMENT OF COMMERCE

National Bureau of Standards

National Measurement Laboratory

Fracture and Deformation Division

National Engineering Laboratory

Automated Production Tachnology Division

Washington, D.C. 20234

Boulder, CO. 80303

December 1981

Issued August 1982

Prepared for

Office of Naval Research

Cepartment of the Navy

Arlington, VA 22217

Annual Technical Report

1 October 1980-30 September 1981

Contract No. N00014-81-F-0010

Reproduction in whole or part is permitted for any purpose of the United States Government

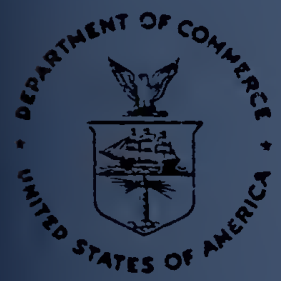

U.S. DEPARTMENT OF COMMERCE, Malcolm Baldrige, Secretary

NATIONAL BURFAU OF STANDARDS, Ernest Ambler, Director 

NBSIR $82-2542$

\section{Micromechanical Properties of Beryllium and Other Instrument Materials}

U.S. DEPARTMENT OF COMMERCE

National Bureau of Standards

National Measurement Laboratory

Fracture and Deformation Division

National Engineering Laboratory

Automated Production Technology Division

Washington, D.C. 20234

Boulder, CO. 80303

December 1981

Issued August 1982

Prepared for

Office of Naval Research

Department of the Navy

Arlington, VA 22217

Annual Technical Report

1 October 1980-30 September 1981

Contract No. N00014-81-F-0010

Reproduction in whole or part is permitted for any purpose of the United States Government 
ANNUAL TECHNICAL REPORT

TO

OFFICE OF NAVAL RESEARCH

MICROMECHANICAL PROPERTIES OF BERYLLIUM

AND OTHER INSTRUMENT MATERIALS

by

Bruce W. Christ and Robert S. Polvani

Fracture and Deformation Division

and

Robert J. Hocken, Bruce Borchardt, and Tom Charlton

Automated Production Technology Division

National Bureau of Standards

Washington, DC 20234

Report to: Office of Naval Research

Materials Division

$800 \mathrm{~N}$. Quincy Street

Arlington, VA 22217

Contract Monitors: Dr. Bruce McDonald

Dr. Gil London

Contract Number: N00014-81-F-0010

NR039-146 $(9 / 16 / 77)$

December, 1981

Reproduction in whole or in part is permitted for any purpose by the United States Government. 



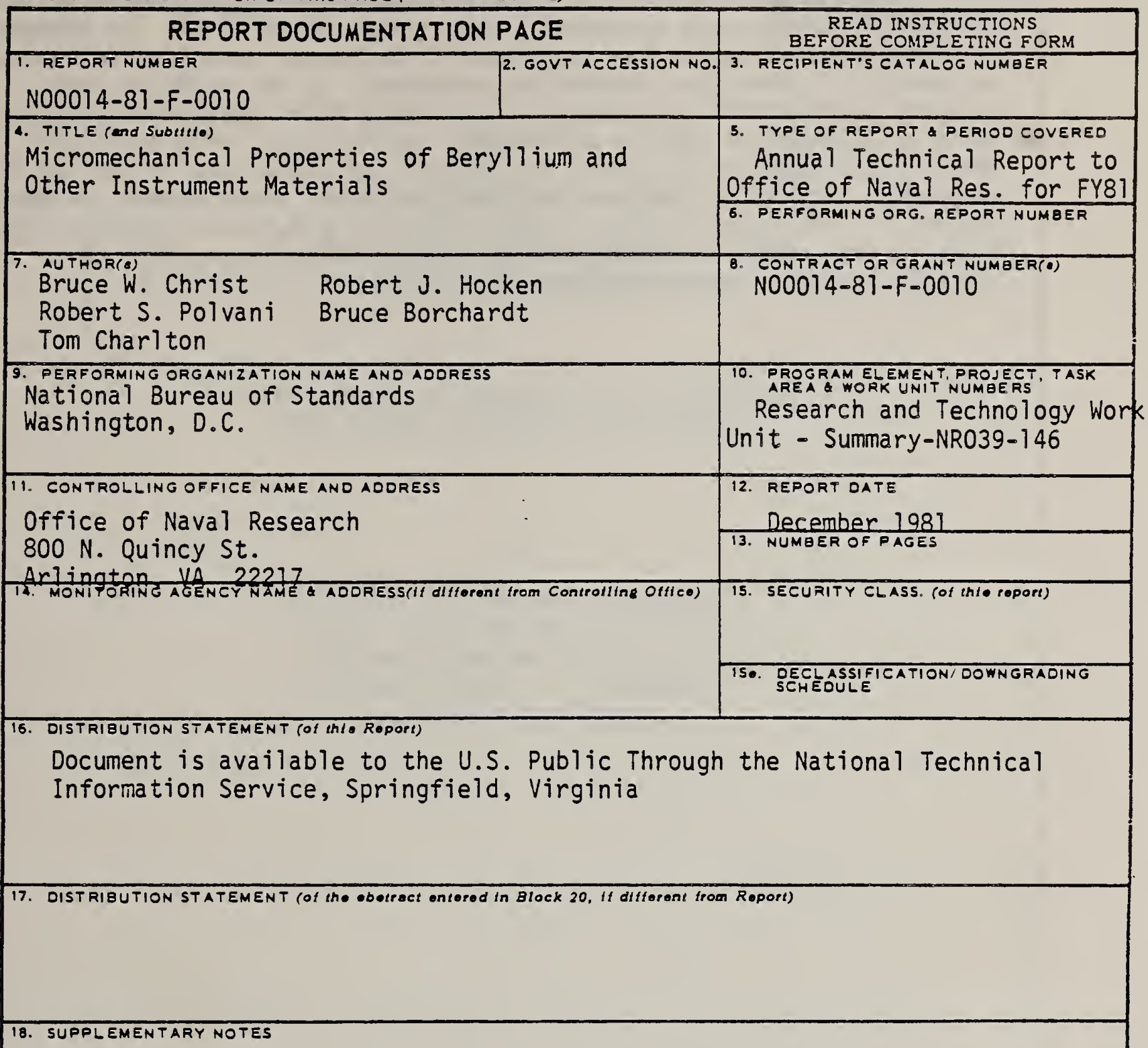

19. KEY WORDS (Continue on reveree elde if neceecary and ldentlty by block number)

Beryllium, Dimensional Stability, Engineering Design, Gyroscopes, Materials Science, Microcreep Rate, Micro-deformation

20. ABSTRACT (Continue on reverse elde If neceecery and identlty by block number)

A program has been underway at the National Bureau of Standards since October 1977 to measure and understand the microcreep of materials used in gyroscopes so that dimensional instability can be improved. A methodology for microcreep testing has been developed and is described herein. Tensile microcreep test results between room temperature and $62^{\circ} \mathrm{C}$ on I-400 beryllium indicate that the microcreep strain does not exceed $10 \times 10^{-6}$ in three months for applied stresses up to $20,000 \mathrm{psi}$. The microcreep rate of I-400 beryllium does not appear to 
be strongly temperature dependent in the range, 45 to $90^{\circ} \mathrm{C}$. The phenomenon of microcreep exhaustion has been demonstrated experimentally and interpreted in terms of dislocation deformation processes. It is suggested that suitable micromechanical procesșing to promote microcreep exhaustion might serve as a method to improve dimensional stability of I-400 beryllium. The possible existence of a correlation between the microcreep stress required to produce a given strain rate and the $0.2 \%$ offset yield stress has been explored. This report includes descriptions of efforts to develop instrumentation to measure uniaxial strain at $62^{\circ} \mathrm{C}$ in the range, $10^{-8}$ to $10^{-7}$ and biaxial strains at room temperature in the range, $10^{-5}$ to $10^{-6}$. 


$$
\text { Part } A
$$

\section{ANNUAL TECHNICAL REPORT \\ to \\ OFFICE OF NAVAL RESEARCH \\ MATERIALS DIVISION}

MICROMECHANICAL PR.OPERTIES OF BERYLLIUM: AND OTHER INSTRUMENT MATERIALS

by

B. W. Christ and R. S. Polvani

Fracture and Deformation Division

Center for Materials Science

National Bureau of Standards

Washington, DC 20234 

PART A

ABSTRACT

A program has been underway at the National Bureau of Standards since ictober 1977 to measure and understand the microcreep of materials used in gyroscopes so that dimensional instability can be improved. A methodology for microcreep testing has been developed and is described herein. Tensile microcreep test results between room temperature and $62^{\circ} \mathrm{C}$ on $\mathrm{I}-400$ bery 11 ium indicate that the microcreep stain does not exceed $10 \times 10^{-6}$ in three months for applied stresses up to 20,000 psi. The microcreep rate of I-400 beryllium does not appear to be strongly temperature dependent in the range, 45 to $90^{\circ} \mathrm{C}$. The phenomenon of microcreep exhaustion has been demonstrated experimentaliy and interpreted in terms of dislocation deformation processes. It is suggested that suitable micromechanical processing to promote microcreep exhaustion might serve as a method to improve dimensional stability of I-400 beryllium. The possible existence of a correlation between the microcreep stress required to produce a given strain rate and the $0.2 \%$ offset yield stress has been explored. 

MICROMECHANICAL PROPERTIES OF BERYLLIUM AND

OTHER INSTRUMENT MATERIALS

I. Background of Program

This NBS program was initiated at the National Bureau of Standards on October 1, 1977. It is sponsored by the Materials Division/Office of Naval Research and is carried out in cooperation with a related program at the C. S. Draper Laboratory, Cambridge, MA. These two programs bring together expertise in metallurgy, materials science and engineering, dimensional metrology and gyroscope design.

The problem being addressed is the dimensional instability of critical components of gyroscopes which influence the aim accuracy of missile systems. Dimensional instability results from microcreep. Such instability is an irreversible dimensional change which occurs over long periods of time, e.g., months, in the absence of applied stress. Residual stresses from machining are known to influence the dimensicnal instability of beryllium and other instrument materials. Fitting up stresses which develop during assembly from press fits, springing and torquing can also contribute to dimensional instability.

The objective of these joint programs is to measure and understand the microcreep of materials used in gyroscopes, so that dimensional instability can be improved. Drift in gyroscope alignment has been attributed in part to mass shifts of $10^{-6}$ inches in critical components. Improved dimensional stability is expected to lessen the need to periodically realign gyroscopes in service and thereby improve the long term aim accuracy of missile systems.

At the heart of the NBS program are displacement measurements in the range of $10^{-6}$ to $10^{-8}$ inches. These measurements are made under uniaxial tensile loading using unique capacitance gauges or laser interferometer 
techniques. Some displacement measurements are made on test specimens which have sustained biaxial tensile stresses. To date, the focus in the NBS program has been on beryllium metal. Titanium alloys and stainless steels have also been used in gyroscopes, but they are less attractive than beryllium, which has the most favorable combination of mechanical and physical properties.

Data obtained to date at NBS on the microcreep of beryllium have been transmitted to the C. S. Draper Laboratory staff for use in the design of prototype gyroscopes. The NBS staff has had interactions with staff at gyroscope producers such as Honeywell and Northrup.

II. Microcreep Testing Methodology

The tensile microcreep rate is the tensile microstrain per unit time which occurs at constant stress and temperature under uniaxial tensile loading. The microcreep stress is usually less than or equal to the microyield stress. The relationship between microcreep and macrocreep is illustrated in Figure 1, where the inset magnifies the microcreep region. The microcreep region is essentially a very close look at the very early Stage I portion of the macrocreep curve. The microcreep rate is the instantaneous slope of the curve showing uniaxial strain vs. time. Because of the curvature, there is no unique microcreep rate. A microcreep test record which exhibits an apparent linear steady state behavior can be regarded as a tangent to the microcreep curve. In a test, strains are measurable and distinguishable from one another when the microcreep strain reaches the minimum detectable limit of the strain measuring equipment. In the inset shown in Figure 1 , this limit is designated as $\varepsilon_{\mathrm{m}}$ and is a strain between $10^{-7}$ and $10^{-6}$. 
Following the tradition for identifing stages in the macrocreep record, the microcreep record can be conveniently subdivided into Stage $i$ and Stage $i i$, as shown in the inset in Figure 1. Stage $i$ is short-lived with relatively high microcreep rates $\left(10^{-9}\right.$ to $\left.10^{-12} / \mathrm{sec}\right)$, whereas Stage $i \mathrm{i}$ is longer-lived with relatively low microcreep rates $\left(\leq 10^{-12} / \mathrm{sec}\right)$.

Microcreep testing under uniaxial loading requires extreme care in establishing and maintaining test conditions. For example, temperature control to plus or minus one one-hundredth of a degree is essential for reliable strain measurements in the range, $10^{-6}$ to $10^{-7}$. If a microcreep test runs for 3-months, the temperature control must be maintained precisely for the duration of the test. Precise atmosphere control is also necessary if capacitance gages are used to measure displacements, since the calibration of the gage is dependent on the composition of the medium in the gap between the plates. For example, changes in relative humidity can change calibration significantly.

Alignment of the test system is another major area for precise control. ${ }^{1}$ A guideline for good practice in microcreep testing is to maintain the precision of alignment at $10^{-4}$ radians. Repeated unloading to zero stress, as is sometimes done in microcreep testing to facilitate length-change measurements, can often have an unfavorable influence on alignment. The straightness of the test specimen itself influences alignment, and precise machining practice is required to produce straight and/or concentric specimens. If an extensometer or strain gauges are fastened to the test specimen, the technique for fastening the extensometer is critical to good alignment.

Test specimen surface condition is another critical factor in producing reliable microcreep data. Good machining practice can minimize residual 
stresses from surface damage layers. ${ }^{2}$ Furthermore, suitable heat treating and/or etching can remove surface damage layers and residual stresses.

If a data set is to be generated on several test specimens to establish trends such as the stress and temperature dependence of microcreep rate, good practice requires that all specimens come from the same region of a single piece of stock to ensure similarity of microstructure and chemistry. Good practice also requires that all specimens have the same thermomechanical history.

Microcreep testing is, by its very nature, an extremely slow process. The rate at which data are generated can be as slow as four microcreep curves per year, assuming a 3-month test in a system which operates $100 \%$ of the time and tests one specimen at a time. The rate at which data are generated can be increased if the number of testing systems is increased and/or if the test interval is decreased. Short term tests can sometimes be useful for screening purposes.

If incremental loads are applied to reach the desired microcreep stress, it is possible to monitor strain during the incremental loading process and thereby establish the microyield stress of the specimen being tested. This is useful information for evaluating the metallurgical similarity of several test specimens in a batch.

Some examples of microcreep test records for I-400 beryllium taken from the literature appear in Figure 2. The records shown in Figure $2 a$ indicate an approximately parabolic dependence of microcreep strain on time, whereas the 

record shown in Figure $2 b$ indicates a rather rapid rise initially followed by leveling off. Records of the type appearing in Figures $2 a$ and $2 b$ are arbitrarily designated as "Type $E$ " records for convenient reference. Type $E$ records show a systematic microcreep behavior and can be analyzed to determine microcreep rates at various times and to establish stress and temperature dependence of microcreep rate.

The record in Figure $2 c$ appears a bit uneven, with the only evident trend being a zero slope. This type of record is arbitrarily designated "Type U". Type $U$ records are rot quite as useful as Type $E$ records in establishing microcreep properties. A Type $U$ record may be indicating problems in testing methodology, or it may simply be indicating that the applied stress is insufficient to promote a systematic deformation which is within the detection limits of the testing system. The latter is thought to be the explaination for Figure $2 c^{5}$.

Occasionally, something unexpected shows up in a microcreep data set. For example, Figure $2 a$ does not show the expected systematic trend of increasing microcreep strain with increasing applied stress. This result may be indicating problems in the testing methodology, or it may be indicating that the test specimens do not have similar micromechanical properties, perhaps due to dissimilar microstructures 


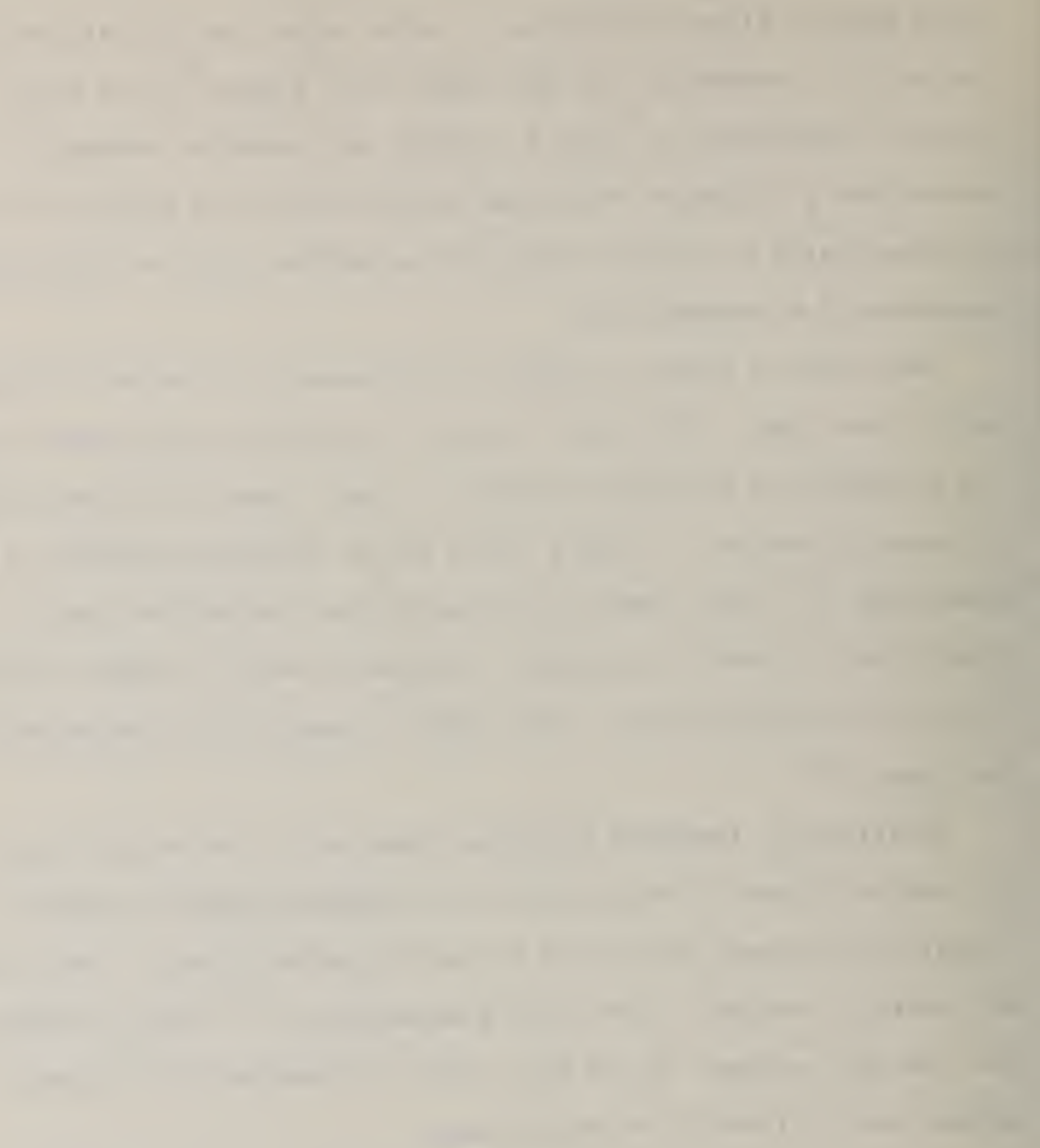


and/or chemistry. Despite this unexpected result, it is clear that the microcreep strain of these specimens of I-400 bery 17 ium at stresses up to 7000 psi for 1500 hours does not exceed $10 \times 10^{-6} \mathrm{in} / \mathrm{in}$.

III. Uniaxial Tensile Microcreep Results on Beryllium Generated at NBS in FY81

\section{A. Experimental}

During FY81, 16 microcreep tests were carried out on 6 specimens of I-400 beryllium. All specimens came from the same region of a single hot pressed billet in order to promote similarity in the microstructure and chemical composition of the material being tested. Machining of all test specimens was carried out in the beryllium machine shop of the C. S. Draper Laboratory, Cambridge, MA, according to a procedure for minimizing surface damage. Heat treatment following rough machining was carried out using the following schedule to minimize residual stresses. Samples were brought to the annealing temperature of $1450^{\circ} \mathrm{F}$ at a rate of 50 Farenheit degrees per hour, held for one hour, then cooled to room temperature at 50 Farenheit degrees per $\mathrm{hr}$. Finish machining was completed using cuts of no more than 0.002 -inches each.

Specimens were tested in a dead weight tensile loading system which is described elsewhere. ${ }^{6}$ Displacements were measured with a parallel-plate capacitance-type extensometer so designed and fastened to the test specimen that precision of alignment could be evaluated throughout the test. Two 

testing systems with a long term minimum detectable limit of $\pm 3 \times 10^{-7}$ inches are currently in use. Microcreep tests were conducted at stresses between 100 and 30,000 psi and at temperatures between 24 and $90^{\circ} \mathrm{C}$. In all tests, precision of alignment was maintained at $\leq 10^{-4}$ radians.

\section{B. Microcreep of I-400 Bery 11 ium at $63^{\circ} \mathrm{C}$}

Several microcreep tests were conducted at $63^{\circ} \mathrm{C}$. This is because gyroscopes in the systems of interest operate at about $63^{\circ} \mathrm{C}$. Some results appear in Figure $3 a$.

Figure $3 a$ illustrates one important aspect of the microcreep behavior of I-400 beryllium, namely that the microcreep strain does not exceed $10 \times 10^{-6}$ in three months for applied stresses up to 20,000 psi. This generalization is supported by other data obtained at room temperature on different lots of I-400 in three other laboratories. ${ }^{3-5}$

Figure $3 a$ shows that the microcreep strain increases significantly when stress increases from 20,000 to 30,000 psi. The fourfold increase in microcreep strain shown in Figure $3 a$ correlates with the applied stress approaching the macroyield stress of I-400 beryllium, which is estimated to be about 50,000 psi.

Figure $3 b$ is a microcreep record for Invar. Data in Figures $3 a$ and $3 b$ were generated on the same testing system at NBS. The overall microcreep behavior and the similarity in behavior for two different materials, I-400 beryllium and Invar, provides reassurance that the testing methodology is satisfactory. 

C. Effect of Temperature on Microcreep of I-400 Beryllium

Figure 4 shows some preliminary test results on the temperature dependence of the microcreep of I-400 beryllium between 45 and $90^{\circ} \mathrm{C}$. The applied stress at all temperatures was 10,000 psi. These results do not show the systematic increase in microcreep rate with increasing temperature which is expected if the microcreep deformation mechanism were thermally activated. The fact that the microyield stress of each specimen tested at 45,75 , and $90^{\circ} \mathrm{C}$ is about $6_{-0}^{+1} \mathrm{ksi}$ indicates that there were no dissimilarities in microstructure or chemistry among these specimens which could account for a variation in microcreep rate. It is tentatively concluded that the microcreep rate of I-400 beryllium is not strongly temperature dependent in the range, 45 to $90^{\circ} \mathrm{C}$. A firmer conclusion must await further test results at various temperatures.

The relatively high microyield stress of the specimen tested at $63^{\circ} \mathrm{C}$, $22.3 \mathrm{ksi}$ vs. $6.0_{-0}^{+1} \mathrm{ksi}$ for the other test specimens in Figure 4 , may account for the greater microcreep resistance shown in the $63^{\circ} \mathrm{C}$ test.

D. Microcreep Exhaustion

An interesting aspect of the microcreep behavior of beryllium is the phenomenon of microcreep exhaustion, which is a decrease in the capacity for continued microstrain in a microcreep test. Microstrain exhaustion is illustrated in Figure 5 , which is taken from Polvani and Christ. ${ }^{8}$ Here, a single specimen of I-400 beryllium at $62^{\circ} \mathrm{C}$ was subjected to seven stress cycles in the range, 1 to $15 \mathrm{ksi}$, Figure $5 \mathrm{a}$. The microcreep strain was measured in each cycle and is plotted in Figure $5 \mathrm{~b}$. The results show that once a critical amount of microcreep strain has occurred, i.e., 10 to 

$20 \times 10^{-6}$, progressively higher stresses do not cause proportionately higher microcreep strains. Rather, the microcreep strain and the microcreep strain rate diminish significantly as the later, higher stresses approach the microyield stress. This result demonstrates that the micromechanical history of a test specimen can have a significant influence on its microcreep behavior.

Figure 6 shows another demonstration of microcreep exhaustion. In this case, a test specimen of I-400 beryllium was loaded three consecutive times to an applied stress of $30,000 \mathrm{psi}$. As the tabulation below shows, the total microcreep strain at 30,000 psi decreased significantly following the first loading, and the microyield stress increased significantly.

TOTAL MICROCREEP STRAIN AND MICROYIELD STRESS

IN CONSECUTIVE LOADINGS AT 30,000 psi

\begin{tabular}{|c|c|c|}
\hline & Total & Microyield \\
\hline Loading & Microcreep Strain & Stress (ksi) \\
\hline First & $78 \times 10^{-6}$ & 12.5 \\
\hline Second & $22 \times 10^{-6}$ & 19.0 \\
\hline Third & $18 \times 10^{-6}$ & 21.9 \\
\hline
\end{tabular}

Furthermore, results in Figure 6 show that microcreep exhaustion seems to: 1) reduce significantly the strain at which Stage $i$ is complete, and 2) reduce significantly the limiting microcreep rate in Stage $i i$.

The test specimen which produced the results in Figure 6 exhibited remarkable stabilty during a 340 hour test at an applied stress of 100 psi and a temperature of $24^{\circ} \mathrm{C}$ after the third loading, as demonstrated in Figure 7. This Type $U$ microcreep record is a further illustration of the concept of microcreep exhaustion. 


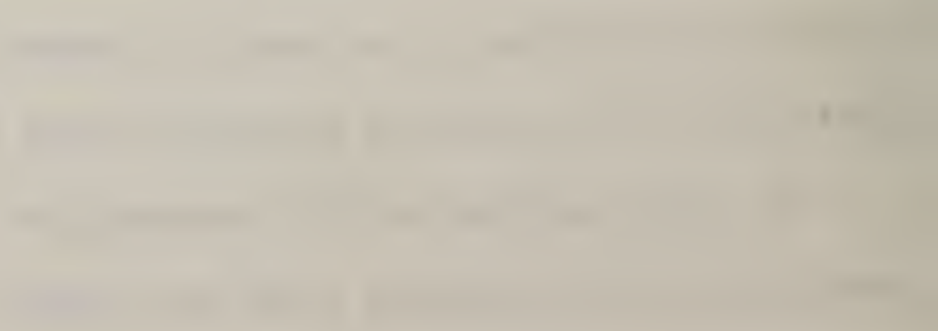


Microcreep exhaustion is explainable in terms of dislocation deformation processes. The following equations relate strain and strain rate to average dislocation density and velocity,

$$
\begin{aligned}
\bar{\varepsilon}_{p} & =b \bar{p}_{m} \bar{s} \\
\dot{\varepsilon_{p}} & =b \bar{\rho}_{m} \bar{v}
\end{aligned}
$$

where

$$
\begin{aligned}
\bar{\varepsilon}_{p}= & \text { average strain } \\
\bar{\varepsilon}_{p} & =\text { average strain rate } \\
b & =\text { Burger's vector } \\
\bar{p}_{m} & =\text { average mobile dislocation density } \\
\bar{v} & =\text { average dislocation velocity } \\
\bar{s} & =\text { average mean free path for individual glide } \\
& \text { dislocations }
\end{aligned}
$$

Since the average dislocation velocity is a single-valued function of the average stress on a dislocation, microcreep exhaustion results from the reduction in the average mobile dislocation density through source depletion and/or immobilization of glide dislocations. Only significantly higher stresses will promote further microcreep strain and maintain microcreep strain rate through increased dislocation velocity and possibly activation of new dislocation sources.

Results in this section suggest that suitable micromechanical processing might serve as a method to promote dimensional stability of I-400 beryllium. For example, unaxial tensile microdeformation might serve to stabilize gyroscope components such as rods and screws which support tensile loads in service. Multiaxial microdeformation might be explored as a means to promote dimensional stability of gyroscope components which support multiaxial stresses. It seems worthwhile to consider exploring the phenomenon of microcreep exhaustion in other grades of beryllium as well as other materials. 

E. Correlation Between Microcreep Rate, Microyield Stress and Yield Stress

There is some interest in determining whether or not correlations exist between the microcreep rate, the microyield stress, and the $0.2 \%$ offset yield stress for the different grades of beryllium. Such correlations would be useful for materials selection and materials procurement because easy-to-obtain test results, namely, macroyield stresses, could serve as the basis for estimating results of the more difficult micro-measurements. The possibility of establishing such correlations on a fundamental basis rests on whether or not the deformation processes during microcreep, microyielding and macroyielding are the same. Data by Bonfield indicate that they are. ${ }^{9}$ It is expected that they would be the same if: 1) The microstructures are essentially the same from grade to grade,i.e., same dislocation sources and same barriers to dislocation glide, and 2) the difference in stress amplitude between micro- and macro-plasticity does not change the deformation process significantly. It has been pointed out that single crystal test results show that only basal plane slip occurs at stresses below about $1 \mathrm{ksi} i^{10}$. Although this change in slip mode may have some influence on correlations, some preliminary attempts at correlations have been made, with results shown in Figures 8 and 9.

The trend 1 ine in Figure 8 indicates that the microcreep stress increases as the microyield stress increases. Specifically, it indicates that a 21,000 psi increase in the applied creep stress is required to produce a microcreep rate of $1.1 \times 10^{-13} / \mathrm{sec}$. When microyield stress increases from 10,000 to 48,000 psi. Two different grades of beryllium were used to establish this trend line. The slope is about 0.5. It is conceivable that the slope of the correlation plot varies with the microcreep rate at which it is determined. A 

positive intercept of about $2 \mathrm{ksi}$ on the applied creep stress axis is indicated by extrapolation in Figure 8 , though the meaning is not clear. A zero intercept seems physically reasonable. Clearly, there is a need to obtain more data to thoroughly investigate this proposed correlation. If a correlation is substantiated, one consequence would be that the variability in microyield stress from one production lot to another, Figure 9, could result in significant variability in the applied stress required to produce a given microcreep rate.

Figure 9 is a plot of micro- and macro-yield data from the production quality control records of a commerical producer. This plot indicates that the microyield stress increases as the $0.2 \%$ offset yield stress increases. The strain rate at which the yield stress was determined was not reported. The slope is about 01.5. Extrapolation of the trend line indicates a zero intercept, which is physically reasonable. This plot is made from data from four grades of beryllium. The range of stresses results from 1) the inherent stress differences from one grade to another, and 2) the inherent scatter in strength from one billet to another, and 3) possibiy a variation in the strain rate at which the yield stress was determined.

Combining the slopes of the linear trend lines in Figure 8 and 9 and ignoring the possibility of a non-zero intercept in Figure 8 , gives the following correlation between the microcreep stress required to produce a microcreep strain rate of about $10^{-13} / \mathrm{sec}$ and the $0.2 \%$ offset yield stress,

$$
\sigma_{\text {mcr }}=0.075 \text { (Y.S.) }
$$

It is possible that the coefficient in this correlation equation varies slightly with the strain rate at which the microcreep stress is determined. Nevertheless, this correlation can serve as a first approximation to assist designers in the matter of material selection. 
IV. Conclusions

1. A testing methodology has been established at NBS during the last four years for microcreep testing of materials under constant stress uniaxial tensile loading. Reliable results have been obtained in the strain range, 1 to $100 \times 10^{-6}$, on I-400 beryllium test specimens. The testing methodology involves careful control of temperature, humidity, and alignment. Furthermore, the testing methodology requires careful control of the geometry, dimensions, surface condition and metallurgical structure of the test specimens. Lastly, the testing methodology requires that the parallel plate capacitance extensometers used to measure displacements be fastened carefully to the test specimens.

2. Generation of microcreep data is a very slow process. Under optimum conditions, a single-specimen testing system can produce four three-month test records per year.

3. Microcreep test records of microcreep strain vs. time at constant stress can be classified in one of two categories:

a) A Type $E$ record shows a rapid initial rise (Stage i) followed by a gradual asymptotic approach to some limiting microcreep strain rate (Stage $i i)$. This type of record is useful for quantitative analysis of microcreep properties.

b) A Type $U$ record shows an uneven, nearly-level trace with the only evident trend being a zero slope. A Type $U$ record may be indicating problems in the testing methodology or it may be indicating that the applied stress is insufficient to promote a systematic deformation which is within the detection limits of the testing system. 


\section{$\sqrt{2}$}


4. The microcreep strain rate of I-400 bery 11 ium at $62^{\circ} \mathrm{C}$ which exhibits a Type $E$ microcreep record is typically $10^{-9}$ to $10^{-12} / \mathrm{sec}$ in Stage $i$ and $\leq 10^{-12} / \mathrm{sec}$ in Stage $\mathrm{ii}$. About 70 to $80 \%$ of the microcreep strain in a Type $E$ test record occurs in the first 100 hours.

5. The microcreep strain of I-400 bery 11 ium at $62^{\circ} \mathrm{C}$ does not exceed $10 \times 10^{-6}$ in three months for applied stresses up to 20,000 psi.

6. Microcreep tests were carried out on I-400 beryllium at temperatures of $45,62,75$ and $90^{\circ} \mathrm{C}$. From these test results, it is tentatively concluded that the microcreep rate of I-400 beryllium is not strongly temperature dependent in the range, 45 to $90^{\circ} \mathrm{C}$. A firmer conclusion must await further test results at various temperatures.

7. I-400 beryllium tested in uniaxial tension exhibits microcreep exhaustion which is a decrease in the capacity for continued microstrain in a microcreep test. The discovery of microcreep exhaustion suggests that suitable micromechanical processing might serve as a method to promote dimensional stabilty of I-400 beryllium. Multiaxial microdeformation might be explored as a means to promote dimensional stability in design situations where multiaxial stresses must be supported.

8. An approximate correlation between the microcreep stress required to produce a given strain rate and the $0.2 \%$ offset yield stress has been established for different grades of beryllium, as follows:

$$
\sigma_{\text {mer }}=0.075 \text { (Y.S.) }
$$



Acknowledgments

The following individuals have given valuable assistance to various facets of this test program: Mr. C. S. Tilghman helped with the experimental measurements; Dr. J. Filiben and Mr. S. Leigh developed computer codes that were used to analyze and graph the microcreep records; Dr. C. Reeve developed a method for extrapolating microcreep curves with a high degree of statistical reliability; Dr. R. deWit assisted Dr. C. Reeve by carrying out a critical evaluation of the technique for extrapolating microcreep curves. 



\section{REFERENCES}

1. B. W. Christ and S. R. Swanson: "Alignment Problems in the Tensile Test," ASTM Journal of Testing and Evaluation, Vol. 4, No. 6, Nov. 1976, pp. 405-417.

2. National Materials Advisory Board: "Evaluation Test Methods for Beryllium," National Academy of Sciences, National Research Council, Washington, D.C. Report No. MAB - 205 - M (1966).

3. C. W. Marschall, R. E. Maringer and F. 1. Cepollina: AIAA Paper No. 72-325, 13th Structures Structural Dynamics and Materials Conf., San Antonio, TX. April 10-12, 1972.

4. H. S. Starrett: "An investigation of the Dimensional Stability of Beryllium and Beryllium Oxide". Southern Research Institute, Birmingham, AL. (1966) SRI Report to M.I.T., Cambridge, Mass., Pruchase Order IL-4-196951.

5. J. W. Lyons, Jr.: "Absolute Capacitance Microcreep and Dimensional Stability Measuring System," NASA Report No. TM-X-2046 (1971).

6. B. W. Christ, R. S. Polvani, and R. J. Hocken: "Micromechanical Properties of Beryllium and Other Instrument Materials." Annual Technical Report from NBS, Washington, DC to Office of Naval Research, Boston, Massachusetts. October, 1978.

7. B. W. Christ: "Effects of Misalignment on the Pre-Macroyield Region of the Uniaxial Stress-Strain Curve," Metallurgical Transactions, Vol. 4, Aug. 1973, pp. 1961-1965.

8. R. S. Polvani and B. W. Christ: "Microcreep of Instrument Grade Beryllium," SAMPE Quarterly, Vol. 10, No. 4, July 1979, pp. 37-41.

9. W. Bonfield and .C H. Li: "Dislocation Configuration and the Microstrain of Polycrystalline Beryllium," Acta Met., Vol. 11, 1963, pp. 585-90.

10. G. J. Turner and J. S. White: "The Temperature Dependence of the Critical Resolved Shear Stresses for Basal and Prismatic Slip in Beryllium," Scripta Met 6 , 123 (1972). 



\section{PART A \\ APPENDIX I - MICROCREEP-CURVE FITTING TECHNIQUES \\ MICROMECHANICAL PROPERTIES OF BERYLLIUM \\ AND OTHER INSTRUMENT MATERIALS}

\section{INTRODUCTION}

Curve-fitting to microcreep data has been carried out using a computer code called DATAPLOT, which was developed at the National Bureau of Standards to combine curve fitting with graphics. DATAPLOT is a free-format, English-like syntax language for:

1. interactive graphics (continuous or discrete)

2. linear or non-linear fitting

3. general data analysis

4. statistical analysis

5. mathematical analysis

DATAPLOT was developed originally by James J. Filliben of NBS in 1977 in response to data analysis problems encountered at the National Bureau of Standards. It is a valuable tool not only for "raw" graphics, but also for manuscript preparation, modelling, data analysis, data summarization, and mathematical analysis. DATAPLOT may be run either in batch or interactively. DATAPLOT graphics may appear on many different types of output devices. Due to its modular design and underlying ANSI FORTRAN (PFORT) code, DATAPLOT is portable to a wide variety of computers.

\section{CAPABILITIES: Processing and Displaying Data}

All I/O is format-free. File names may be used directly in DATAPLOT READ/WRITE command syntaxes. The many graphical, classical, and exploratory data analysis capabilities listed below serve as tools for the processing and editing of data files. Sorting and ranking capabilities exist.

Graphics capabilities include continuous display terminal plots (e.g., Tektronix), discrete (narrow-width or wide-carriage) terminal plots (e.g., TI 700), high-speed printer plots, high-quality secondary output plots (e.g., Calcomp); on-line interactive definition and plotting of functions; data plots; superimposed mixture of function and data plots; multi-trace plots; linear or log scale plots; plots with or without labels, titles, frames, tic marks, grid lines, legends, legend boxes, arrows, etc.; automatic hardcopying of plots; 3-d plots of functions and/or data; multi-colored graphics; all of above for full data sets or subsets of data.

In addition to the DATAPLOT fitting program called NONLIN has been developed by $C$. P. Reeve to fit the specific non-linear microcreep equation. This program is also helpful in establishing the standard deviation or confidence interval to times much larger than the actual duration of a test. 
.

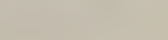



Given the observed microcreep strain values $\varepsilon_{1}, \varepsilon_{2}, \ldots \varepsilon_{n}$ at times $t_{1}, t_{2}$,
$\ldots t_{n}$, the statistical model takes the form,

$$
\varepsilon_{i}=f\left(t_{i}\right)+\mu_{i}
$$

where the $\mu_{i}$ are independent error values from a distribution with mean zero and variance $\Sigma^{2}$.

of several empirical equations which were evaluated, the following equation for microcreep strain seemed to give the best fit most often,

$$
\varepsilon=f(\sigma)=\varepsilon_{0}+A \ln (1+t / B)
$$

where

$$
\begin{aligned}
\varepsilon= & \text { microcreep strain (plastic) } \\
\sigma= & \text { applied stress } \\
\varepsilon_{0}= & \text { a parameter which depends on the test methodology and is to be } \\
& \text { estimated. (Physically, } \varepsilon_{0} \text { is the instantaneous plastic strain } \\
& \text { which occurs when stress is applied to the test specimen). } \\
A, B= & \text { empirical constants to be estimated. }
\end{aligned}
$$

The least squares estimates of $\varepsilon_{0}, A$, and $B$ are termed $\hat{\varepsilon}_{0}, \hat{A}$, and $\hat{B}$. They are obtained by linearizing the above equation with a Taylor series expansion and iteratively solving the linear least squares problems.

The predicted value of microcreep strain at time $t_{i}$ is given by the following least squares estimate,

$$
\hat{\varepsilon}_{i}=\hat{\varepsilon}_{0}+\hat{A} \ln \left(1+t_{j} / \hat{B}\right)
$$

and $\Sigma^{2}$ is estimated by

$$
\Sigma^{2}=\frac{1}{n-3} \sum_{i=1}^{n}\left(\varepsilon_{i}-\hat{\varepsilon}_{i}\right)^{2}
$$

The extrapolated value of microcreep strain at a time $t^{\prime}$ beyond the measured time domain is given by

$$
\begin{aligned}
\varepsilon^{\prime}= & \hat{\varepsilon}_{0}+\hat{A} \ln \left(1+t^{\prime} / \hat{B}\right) \\
& -17 B-
\end{aligned}
$$



The variance of $\varepsilon^{\prime}$ is given by

$$
s_{\varepsilon^{\prime}}^{2}=\left(h^{t} V h\right) s^{2}
$$

where $V$ is the $3 \times 3$ approximate un-normalized variance-covariance matrix of the estimates $\hat{\varepsilon}_{0}, \hat{A}$ and $\hat{B}$, and $h$ is the $3 \times 1$ vector given by

$$
h=\left(\left.\left.\left.\frac{\partial f}{\partial \varepsilon_{0}}\right|_{t,} \frac{\partial f}{\partial A}\right|_{t,} \frac{\partial f}{\partial B}\right|_{t \prime}\right)^{t}
$$

The superscript $t$ denotes matrix transposition.

An approximate $100(1-\alpha) \%$ confidence interval for the true strain at time $t^{\prime}$ is then given by

$$
\varepsilon^{\prime} \pm t_{1-\alpha / 2}(n-3) s_{\varepsilon^{\prime}}
$$

where $t_{1-\alpha / 2}(n-3)$ is the critical point of the $t$ distribution with $n-3$ degrees of freedom at the $\alpha$ level of significance. 



\section{SAMPLE JOB}

Is mecers on 8

II.

18. Drmansion 16018

13.

140 CDD.P $=E-15-\infty$.

Is? हD.

ice.

17.

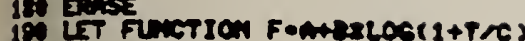

IIT A.e.

210 IIT 8-2.

$x$ Uा CoE.

230

84 ist sof

Q.5 Cory

at:

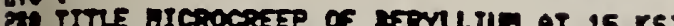

* Vintes NICROSTRAIM

3 XILABEL TIRE (MOLRS)

$310 \times$ XLABEL RUN AT 62 DECREIS CEMTICAADE

320 cRID of

33 CWNACTER SIZE 1.0

30 CWMACTERS $\times$ ILANK

350 LIVES VLAKK SOLID

30 vin 9

3ro $x$ in 360

*ior $s$ us $T$.

phot Pied us T

410.

40.

ai of FILE

A-DATAPLOT PROGRAM

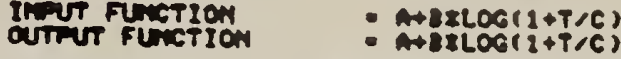

TIE MUE F MA JUST EEEN ECUIUALEMCED

To The FUnCTION

THE COMUUTED UALUE of THE CONSTMN A

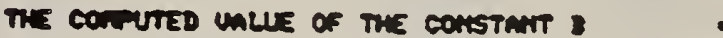

. ลพnmonค1

TE coniuted unue of ThE constant c

acencoses

LEAST SOUARES MOH-LINEAR FIT

SNPLE SIZE $M$.

$\infty 8$

MOOEL $-S=(A+E 2 L O G(1+T / C)$

NO REPLICATION CASE

\begin{tabular}{|c|c|c|c|c|}
\hline $\begin{array}{l}\text { TTURATICM } \\
\text { MULER }\end{array}$ & $\begin{array}{c}\text { COMURCENCE } \\
\text { HEASUEE }\end{array}$ & $\begin{array}{l}\text { RESIDUAL } \\
\text { STAMDARD } \\
\text { DEUIATION }\end{array}$ & 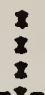 & $\begin{array}{l}\text { PARANETER } \\
\text { ESTINATES }\end{array}$ \\
\hline $\begin{array}{l}2=- \\
2=0 \\
3=0 \\
5-\infty\end{array}$ & $\begin{array}{l}.100-01 \\
.5000-02 \\
.25000-02 \\
.12500-12 \\
.62500-13\end{array}$ & $\begin{array}{r}10458+01 \\
.53378+\infty \\
.51790+\infty \\
.51532+\infty \\
.51528+\infty\end{array}$ & $\begin{array}{l}8 \\
8 \\
7 \\
7\end{array}$ & $\begin{array}{l}.2001 \\
.10801+01 \\
.11316+01 \\
.11494+01 \\
.11547+01\end{array}$ \\
\hline
\end{tabular}

$2000+03$

$.41401+03$

$.57476+03$

$.64071+93$

$.65327+03$
3

Desinual

RESIDUAL STANDARD DEUIATION

B-DATAPLOT RESULTS

MICROCREEP OF I-400 AT $10 \mathrm{KSI}$ AND 63 CENTIGRADE

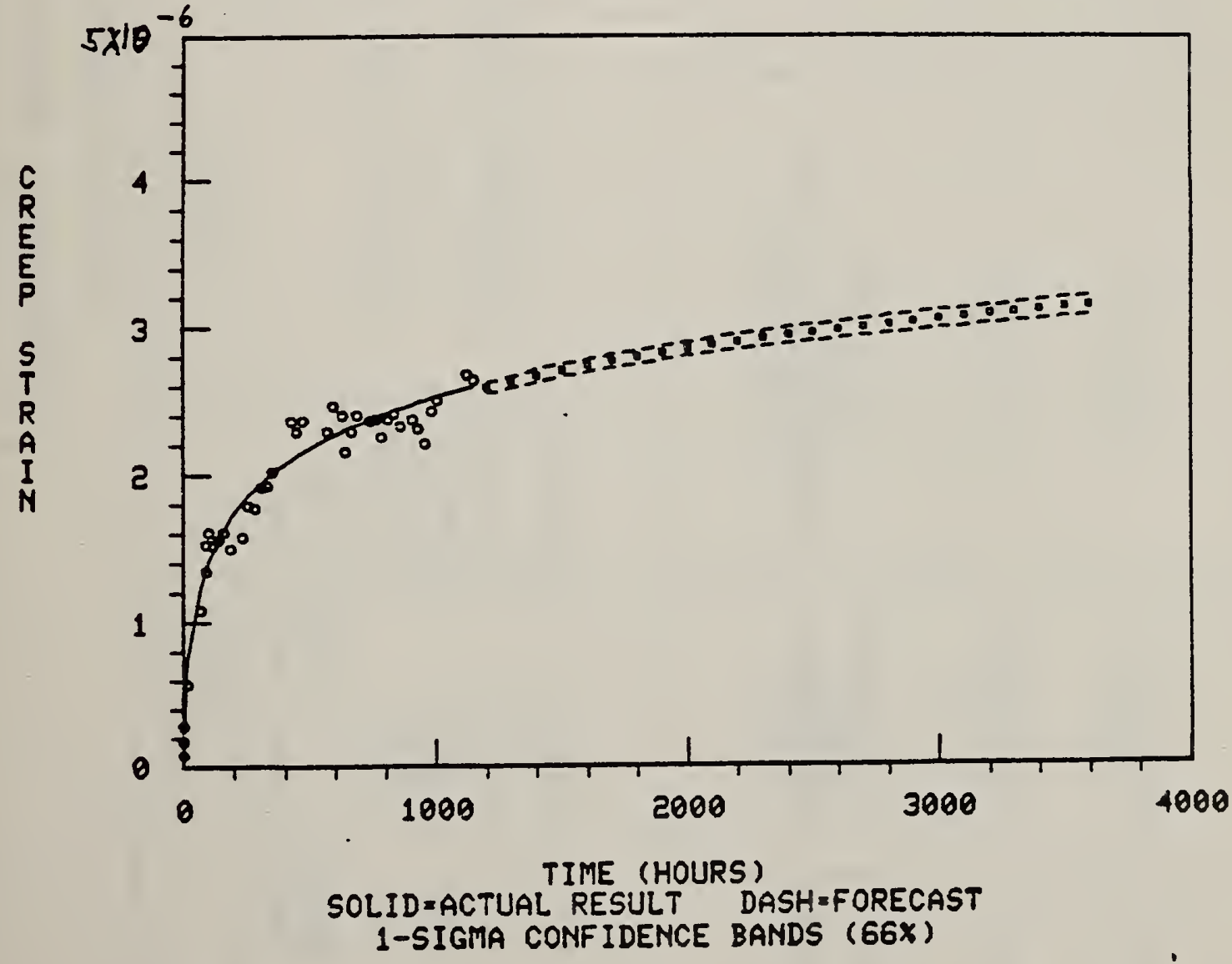

C-EXAMPLE OF EXTRAPOLATION BEYOND THE
MEASURED TIME DOMAIN.

$-17 D-$ 


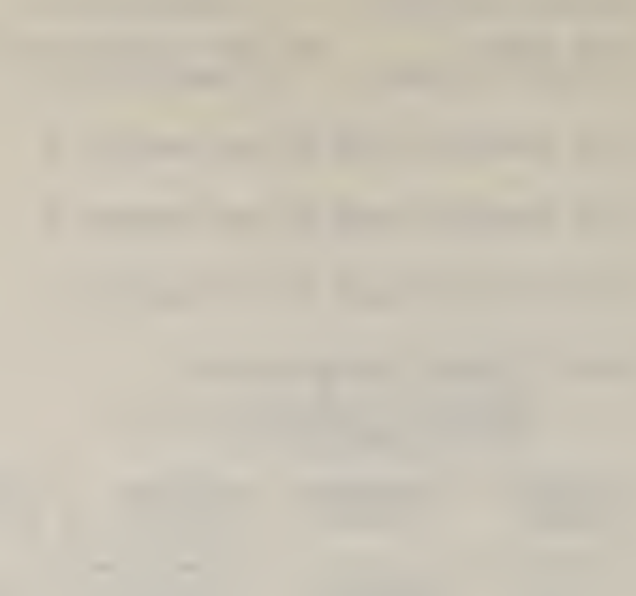




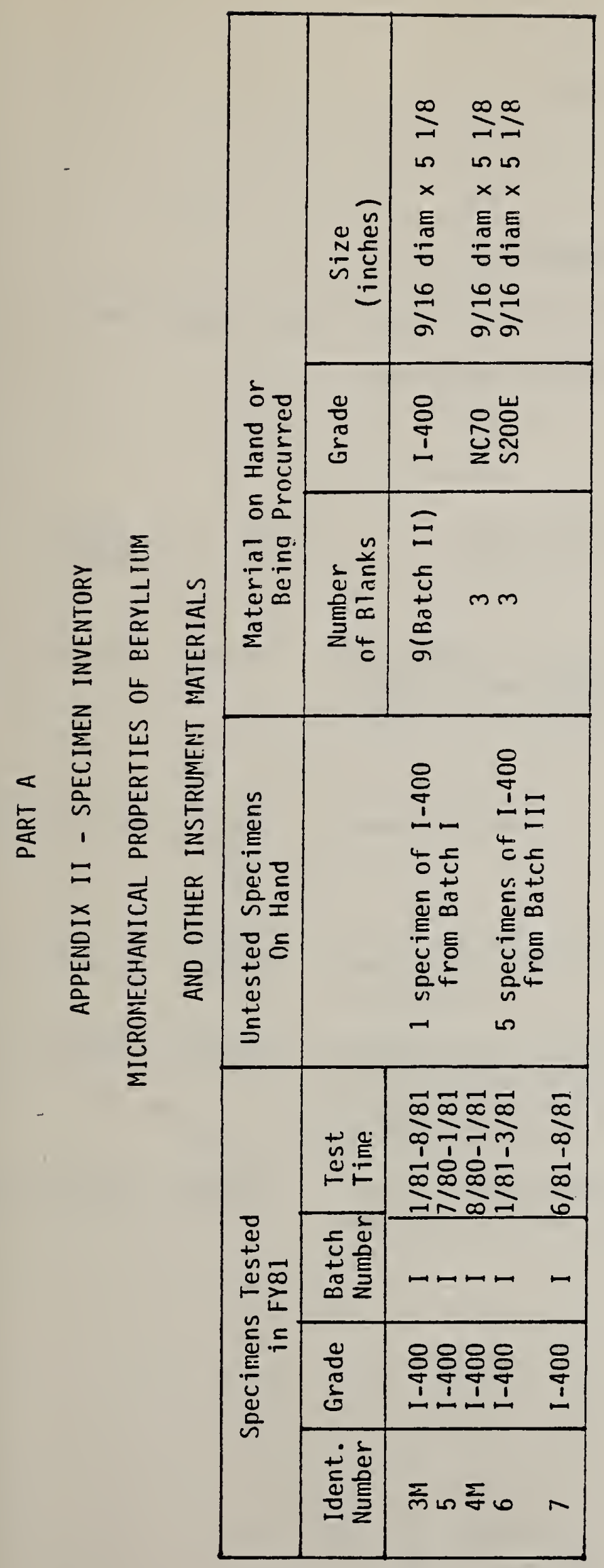

18

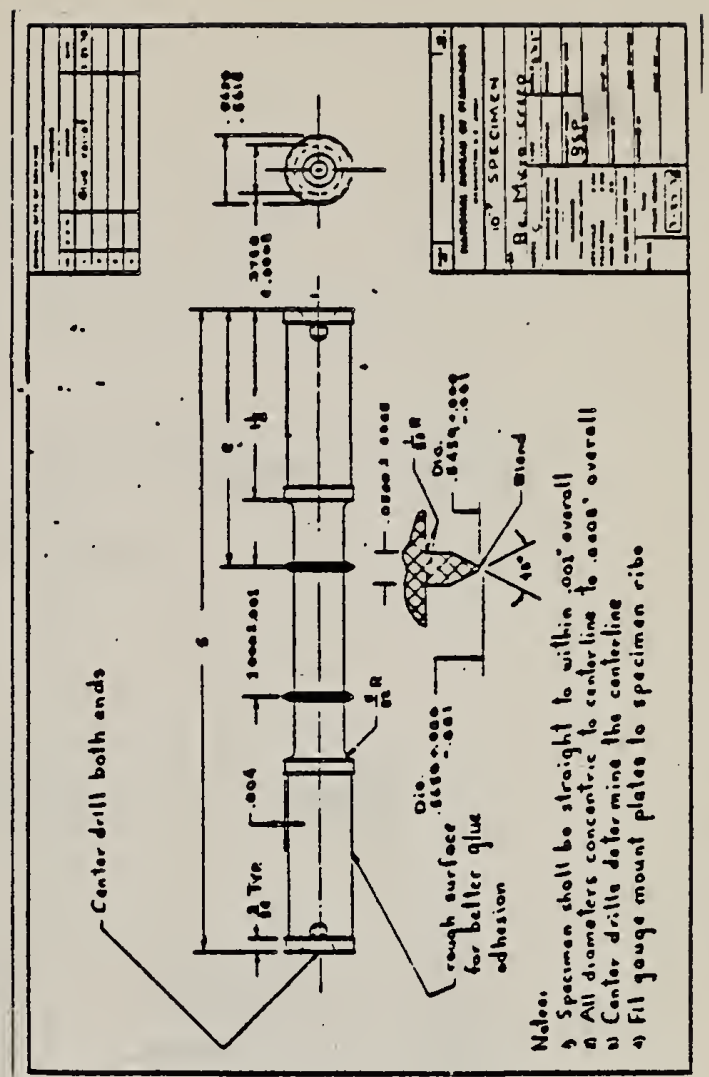

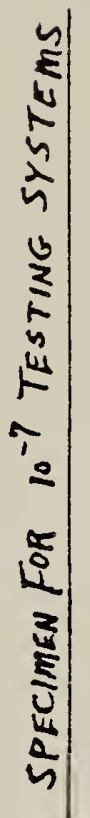

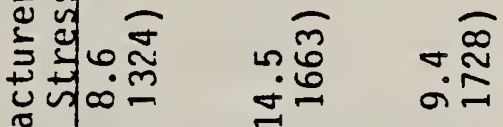

世ै

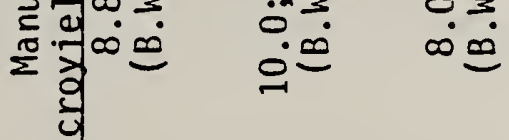

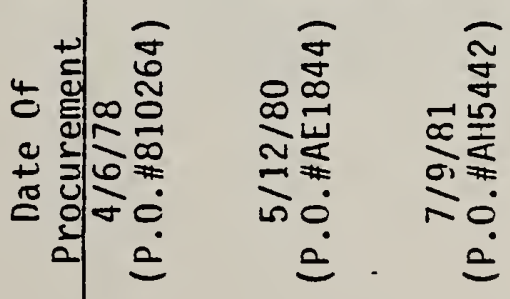

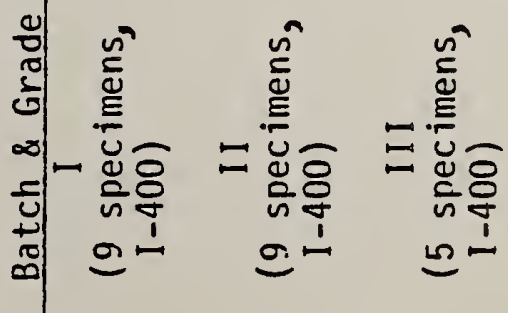



PART A

APPENDIX III

Micromechanical Properties of Beryllium and Other Instrument Materials Presentations and Papers in FY81

Speaker Date Organization and Place $\quad \underline{\text { Title }}$

B. W. Christ 2/11/81 ONR-NBS-C.S. Draper Lab semiannual review meeting, $C$. S. Draper Lab., Cambridge, MA.

R. S. Polvani $2 / 11 / 81$ Same as above

B. W. Christ $3 / 23 / 81$

R. S. Polvani $3 / 24 / 81$

B. W. Christ $5 / 30 / 81$
Westec Conference, Los Angeles, California

Internatinal Conference on Creep and Fracture of Engineering Materials and Structures, Univ. of Wales, U.K.

Staff of NBS Fracture and Deformation Div., Boulder, Co.
Where we have been and where we are going in our quest for microcreep data on gyroscope materials.

Test Results on $\mathrm{I}-400$ Bery 11 ium at $62^{\circ} \mathrm{C}$ and at Stresses Between 300 and 30,000 psi.

Microdeformation in Beryllium

Beryllium Microdeformation Mechanisms

The NBS Program on Microcreep and Dimensional Stability of Materials For Use in Gyroscopes. 



\section{LIST OF FIGURES}

Figure 1 Schematic constant-load, constant temperatüre uniaxial creep record, showing the three major stages of creep. The inset is a schematic showing microcreep records for two stresses. Very small strains are measureable and distinguishable from one another when the strain reaches the minimum detectable limit of the strain measuring equipment, which is designated $\varepsilon_{\mathrm{m}}$ in the inset.

Figure 2 Some typical microcreep test records on I-400 beryllium from the literature.
a) Results from the Battelle/Columbus test program (Ref. 3).
b) Results from the SRI/MIT test program (Ref. 4).
c) Resuits from the NASA test program (Ref. 5).

Figure 3 Some typical microcreep test records from the NBS test program.

a) Results on I-4nO beryllium at $62^{\circ} \mathrm{C}$.

b) Results on Invar at $24^{\circ} \mathrm{C}$.

Figure 4 Effect of temperature on the microcreep strain of I-400 beryllium between 45 and $90^{\circ} \mathrm{C}$.

Figure 5 Microcreep exhaustion in I-400 bery 11 ium tested at $62^{\circ} \mathrm{C}$.

a) Applied stress vs. time.

b) Microcreep strain per stress cycle vs. time.

Figure 6 Microcreep exhaustion in I-400 beryllium in successive tests at $30,000 \mathrm{psi}$ and $63^{\circ} \mathrm{C}$.

Figure 7 Microcreep record on I-400 bery 11 ium $\left(24^{\circ} \mathrm{C}\right)$ after microcreep at $30,000 \mathrm{psi}\left(63^{\circ} \mathrm{C}\right)$ to promote microcreep exhaustion and dimensional stability.

Figure 8 Trend line suggesting correlation between microcreep stress and microyield stress of different grades of beryllium.

Figure 9 Trend line suggesting correlation between microyield stress and $0.2 \%$ offset yield stress. 



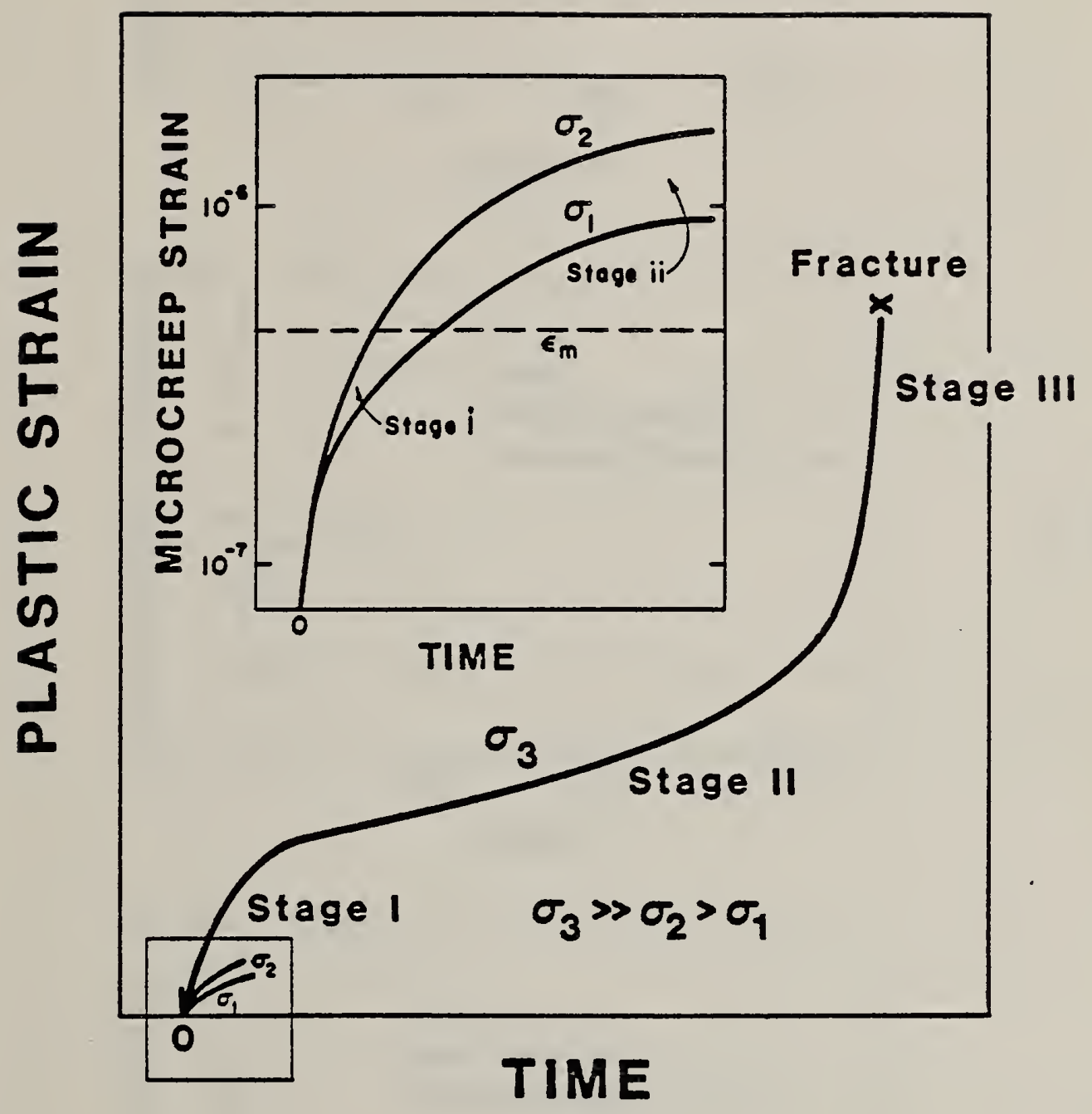

Figure 1 Schematic constant-load, constant temperature uniaxial creep record, showing the three major stages of creep. The inset is a schematic showing microcreep records for two stresses. Very small strains are measureable and distinguishable from one another when the strain reaches the minimum detectable limit of the strain measuring equipment, which is designated $\varepsilon_{m}$ in the inset. 


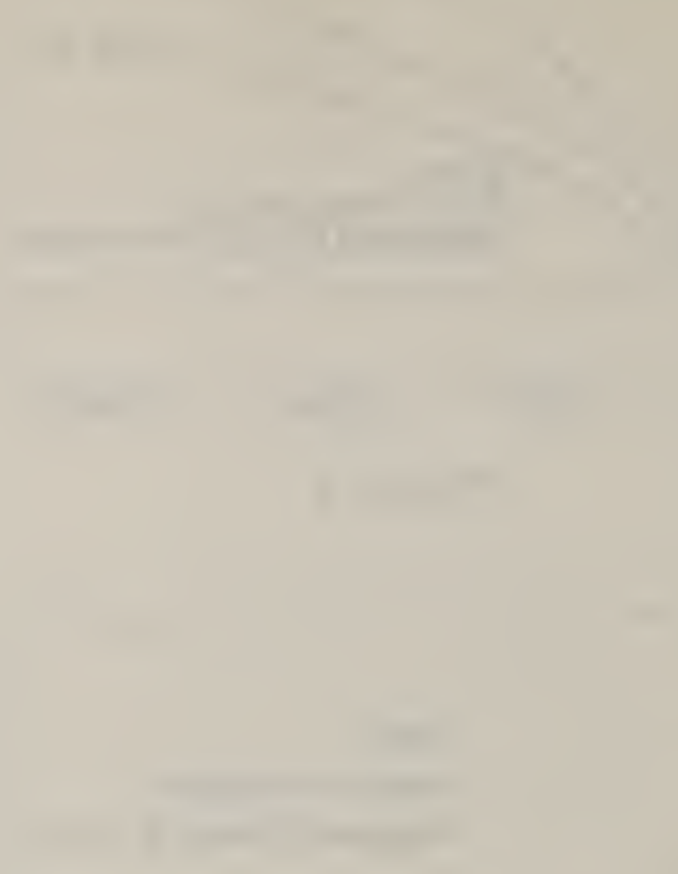

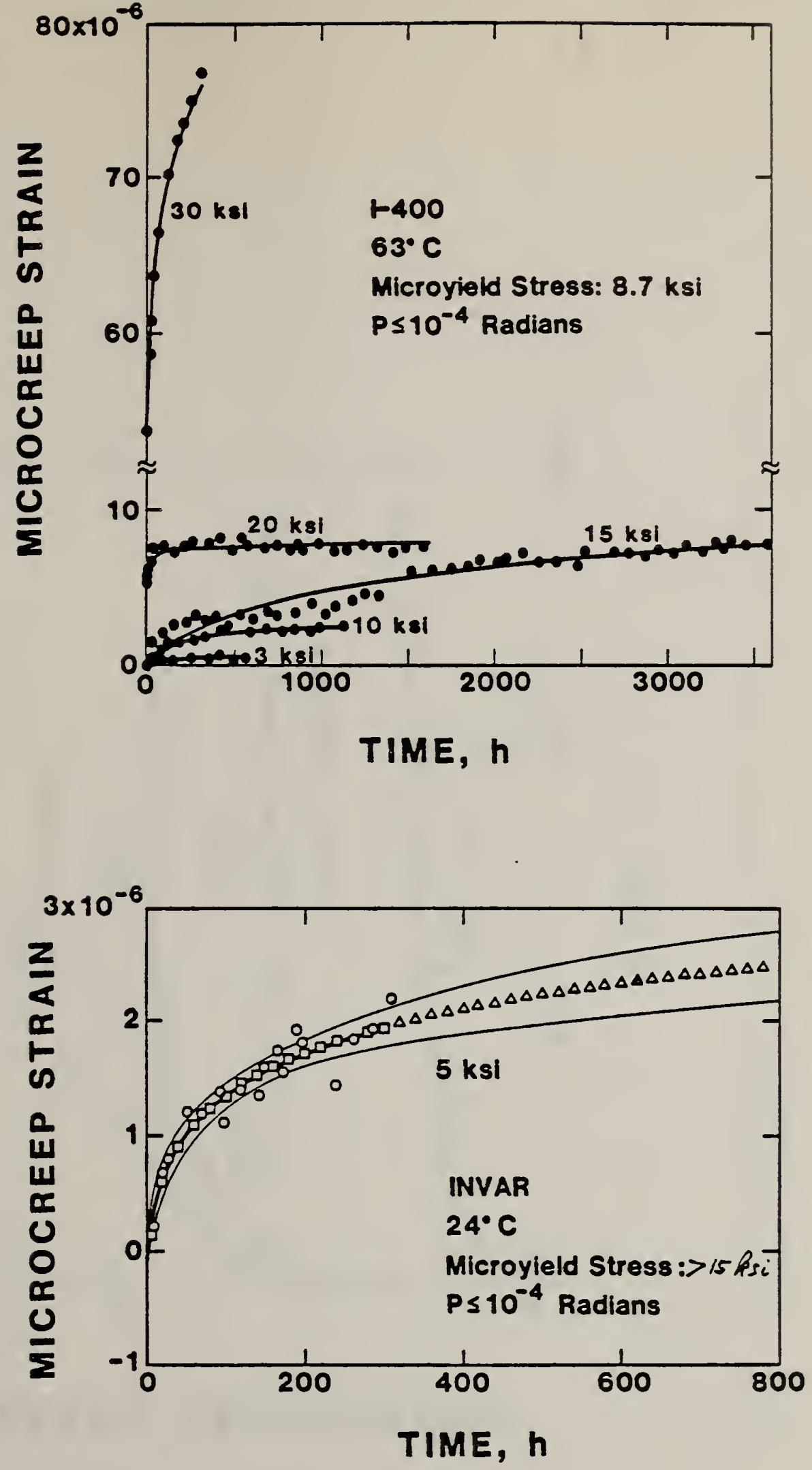

Figure 3 Some typical microcreep test records from the NBS test program.

a) Results on I-400 beryllium at $62^{\circ} \mathrm{C}$.

b) Results on Invar at $24^{\circ} \mathrm{C}$. $10=$ measured data point. $\square$ and heavy solid line $=$ fitted microcreep curve. $\Delta=$ microcreep curve extrapolated beyond time domain of test. Thin solid lines represent the three sigma (99\%) confidence limits of the extrapolation. 



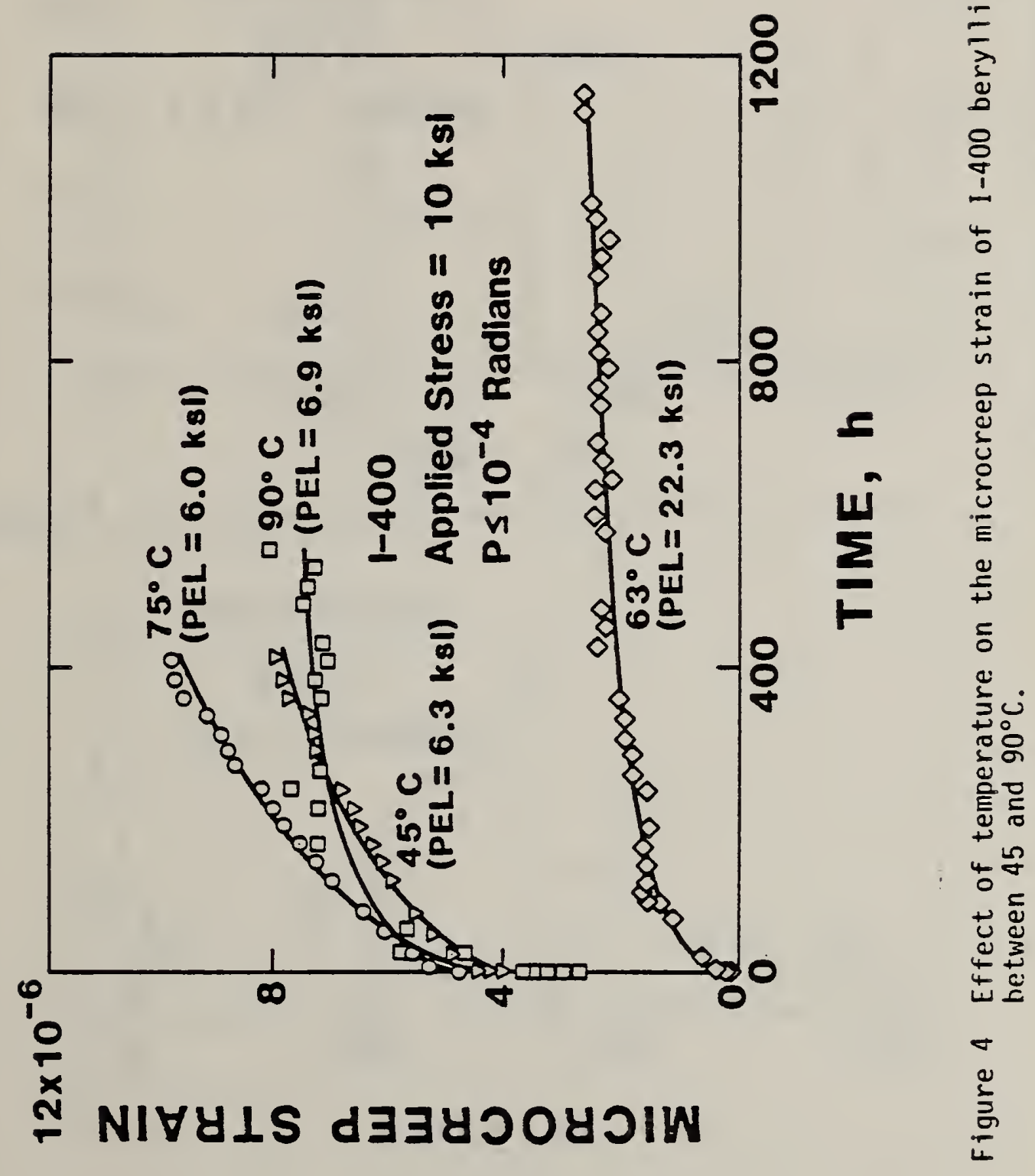




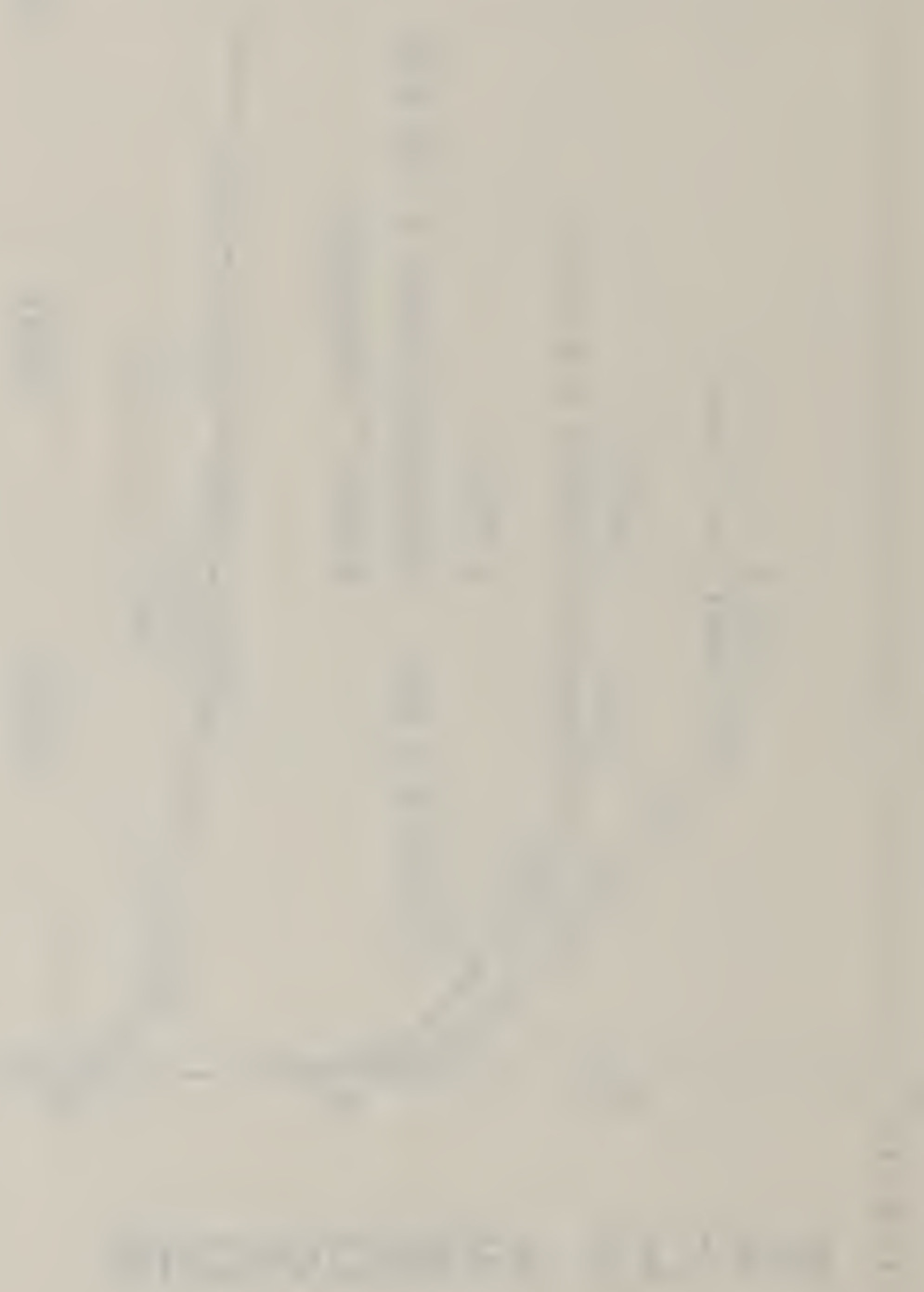




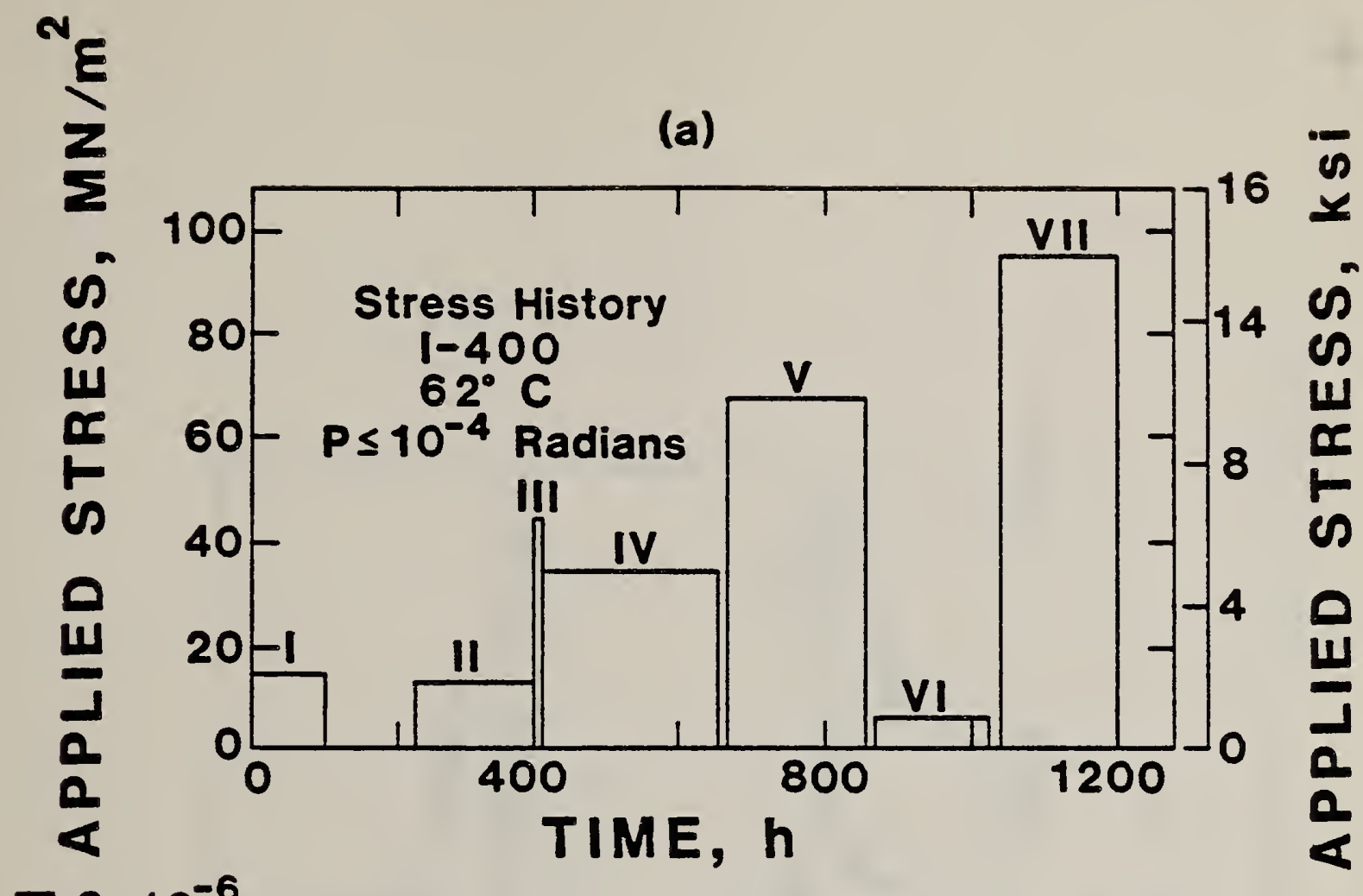

3
3
0
0
0
0
4
0
0
0
0
0
0
2

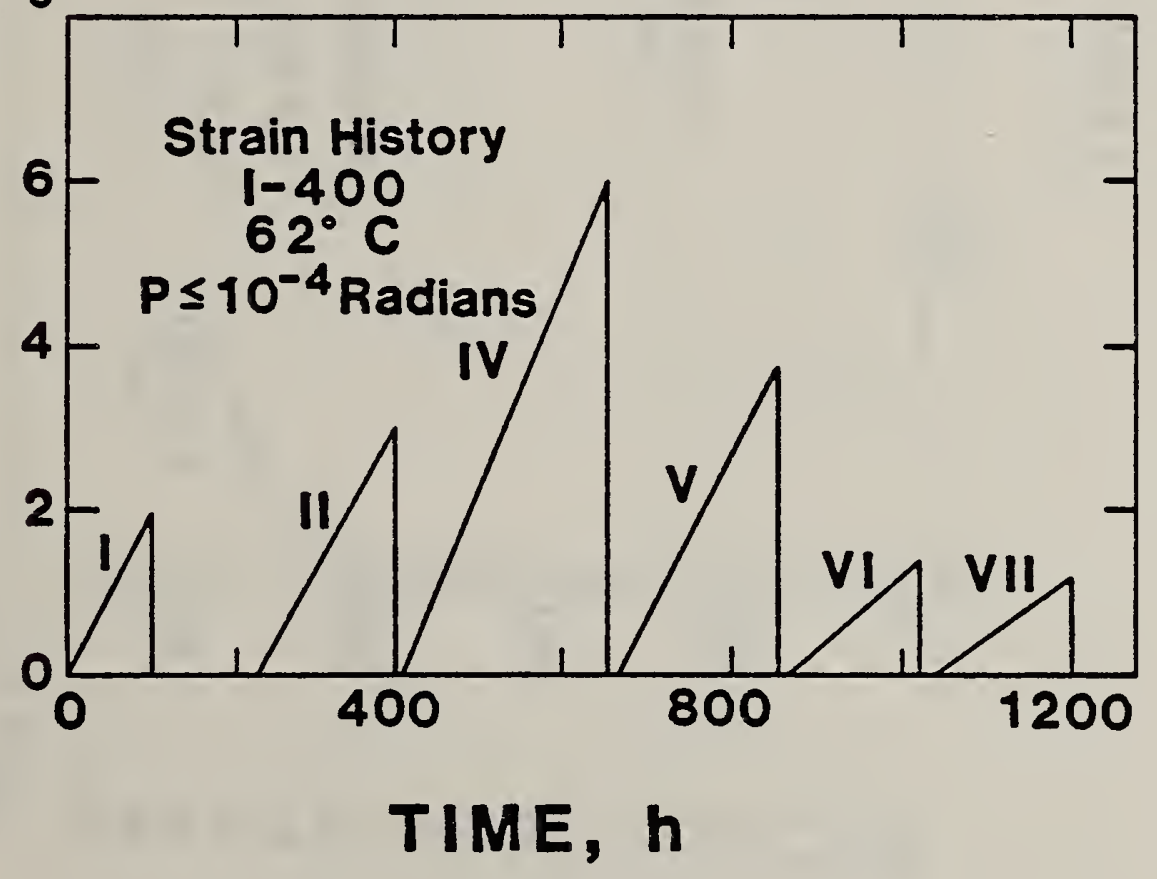

(b)

Figure 5 Microcreep exhaustion in I-400 bery 11 ium tested at $62^{\circ} \mathrm{C}$.

a) Applied stress vs. time.

b) Microcreep strain per stress cycle vs. time. 


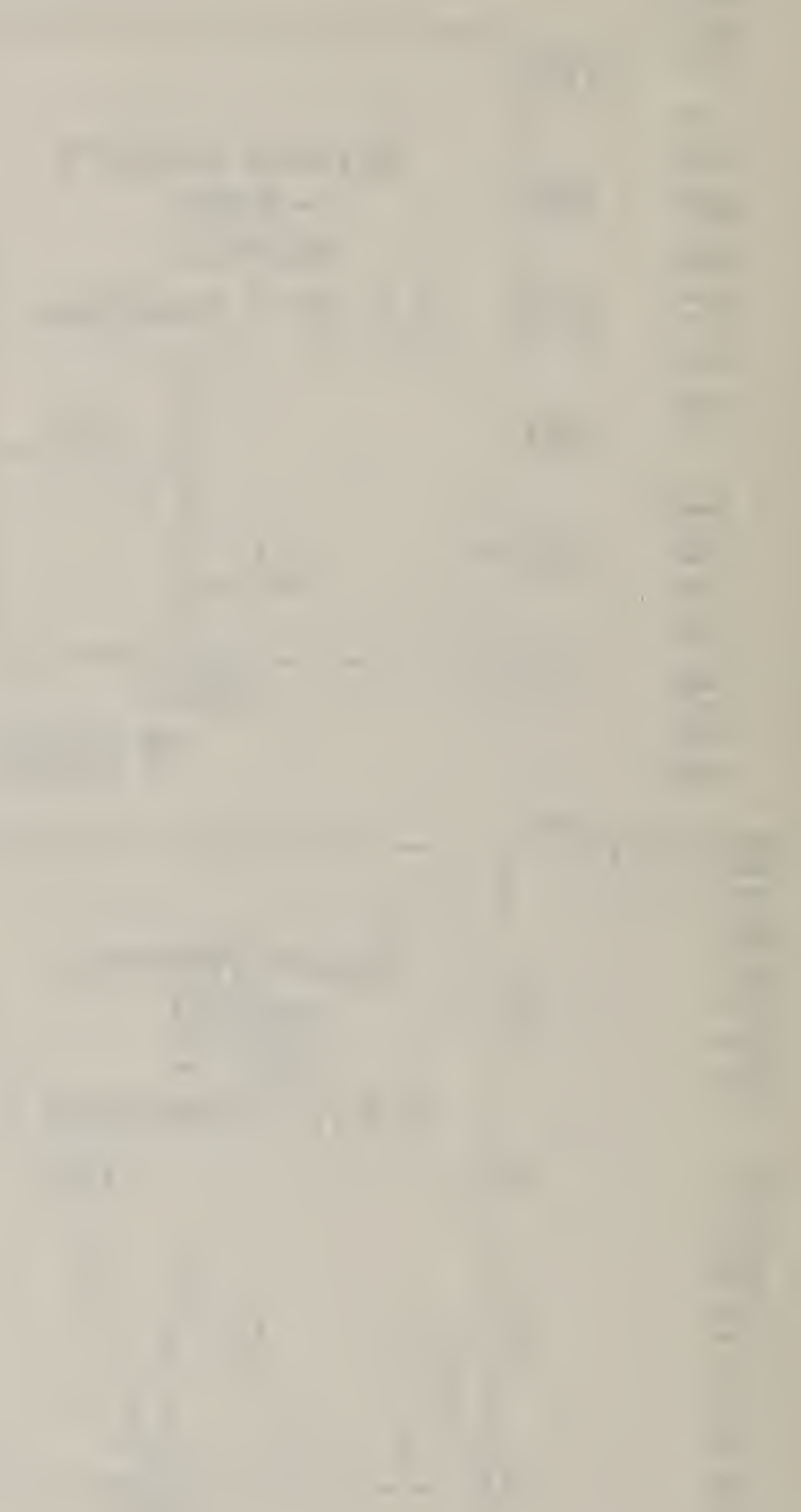




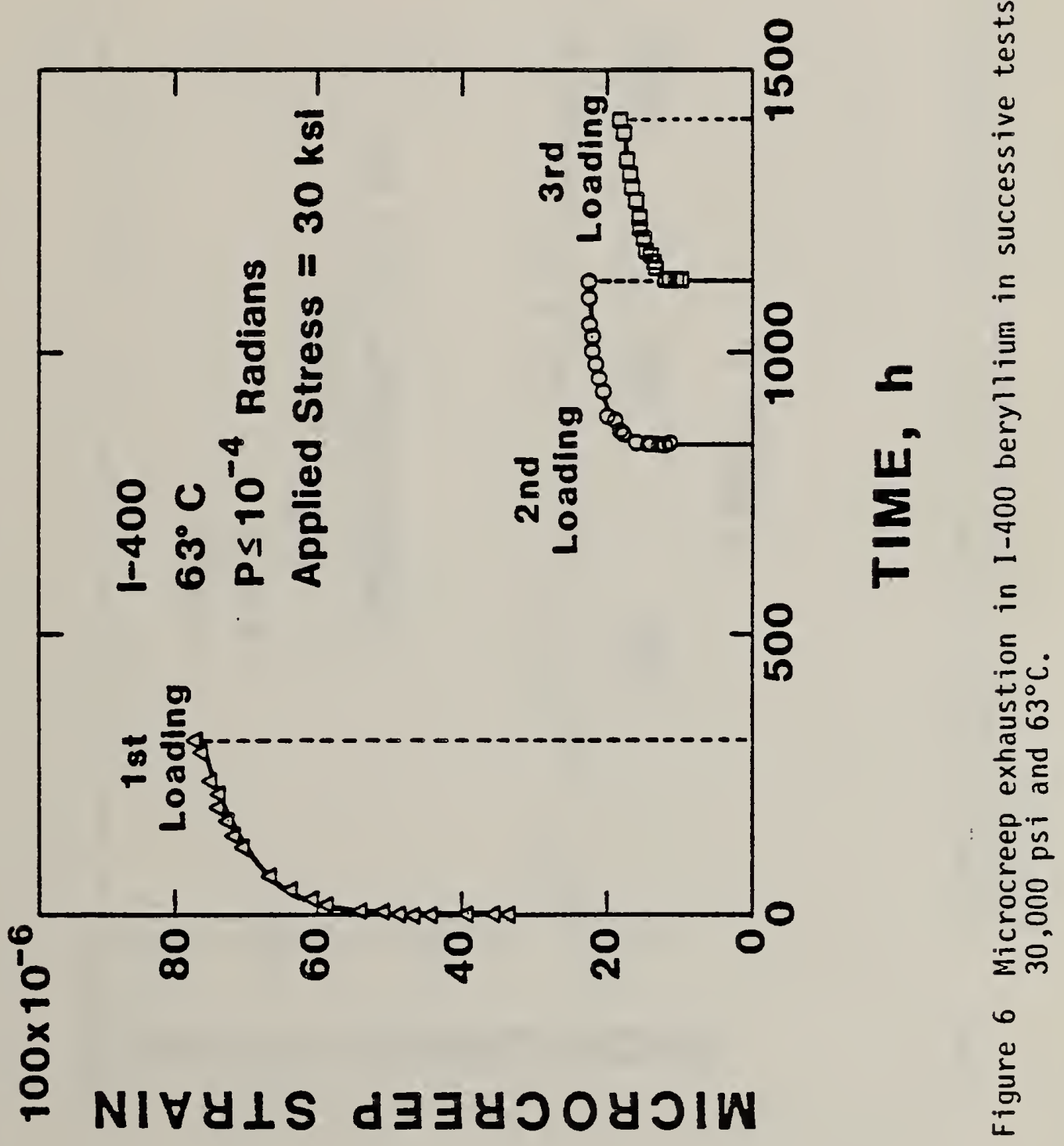




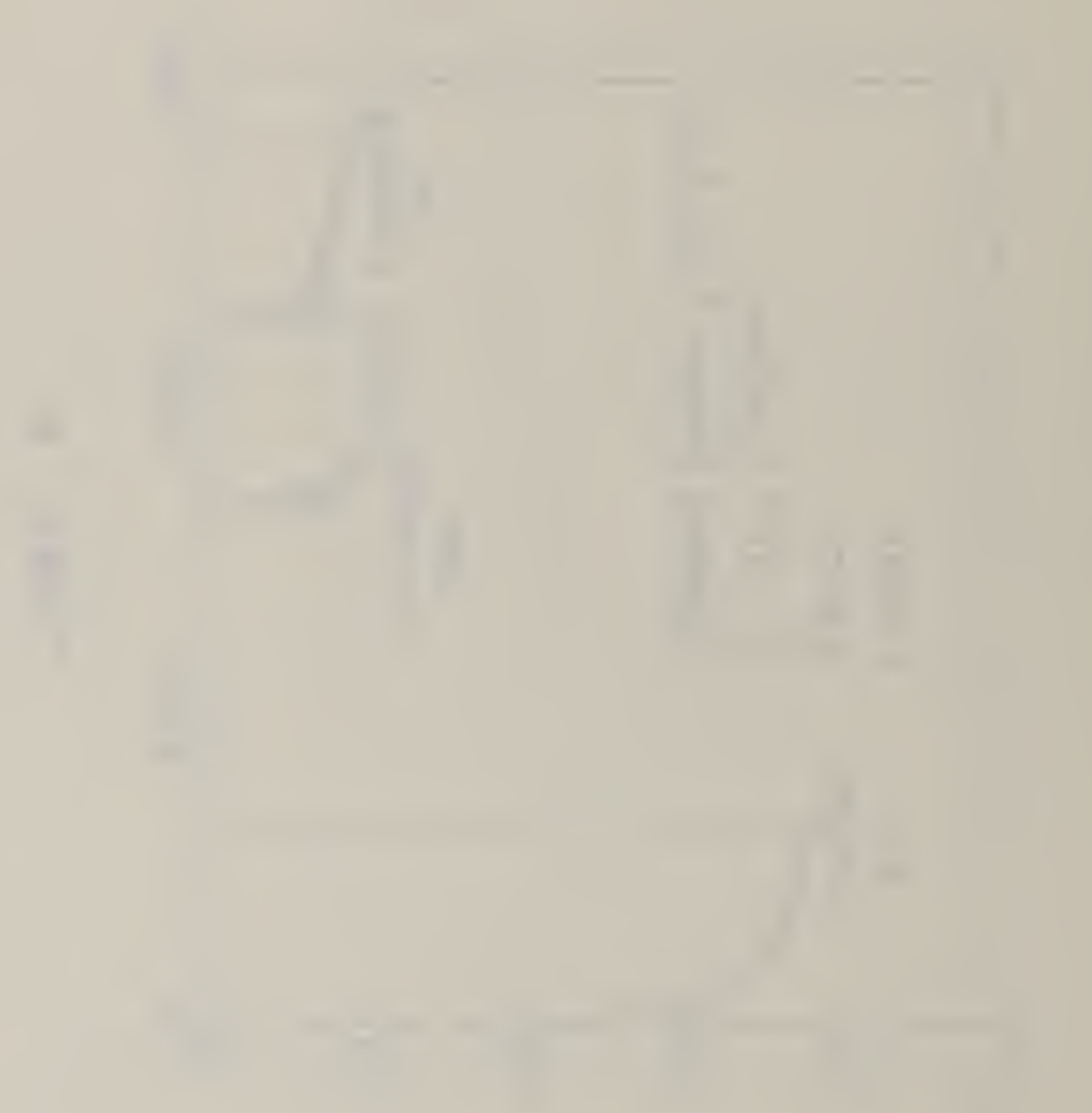



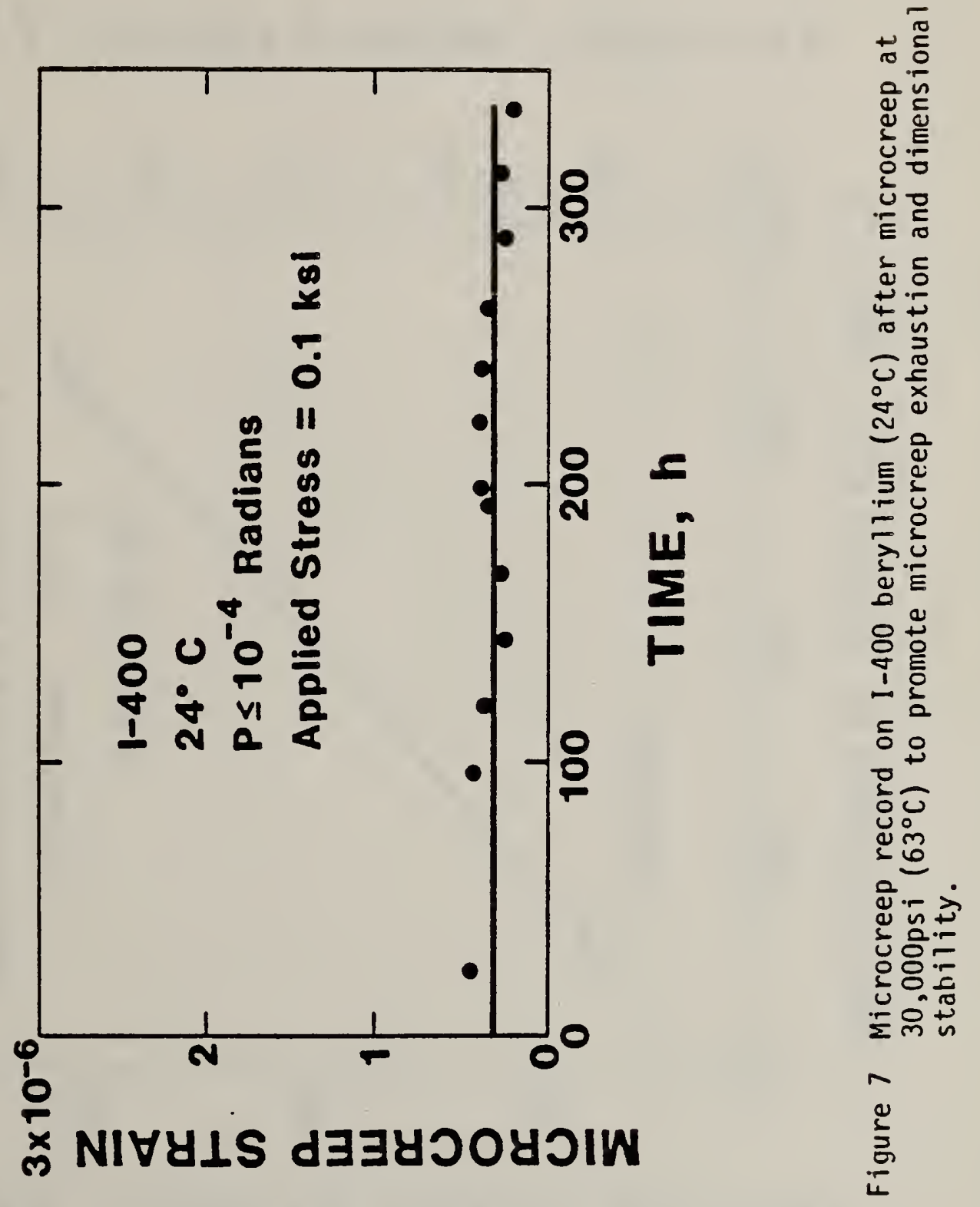



\section{!sy 'SS $341 S$ d $\exists \exists y 0$ a}

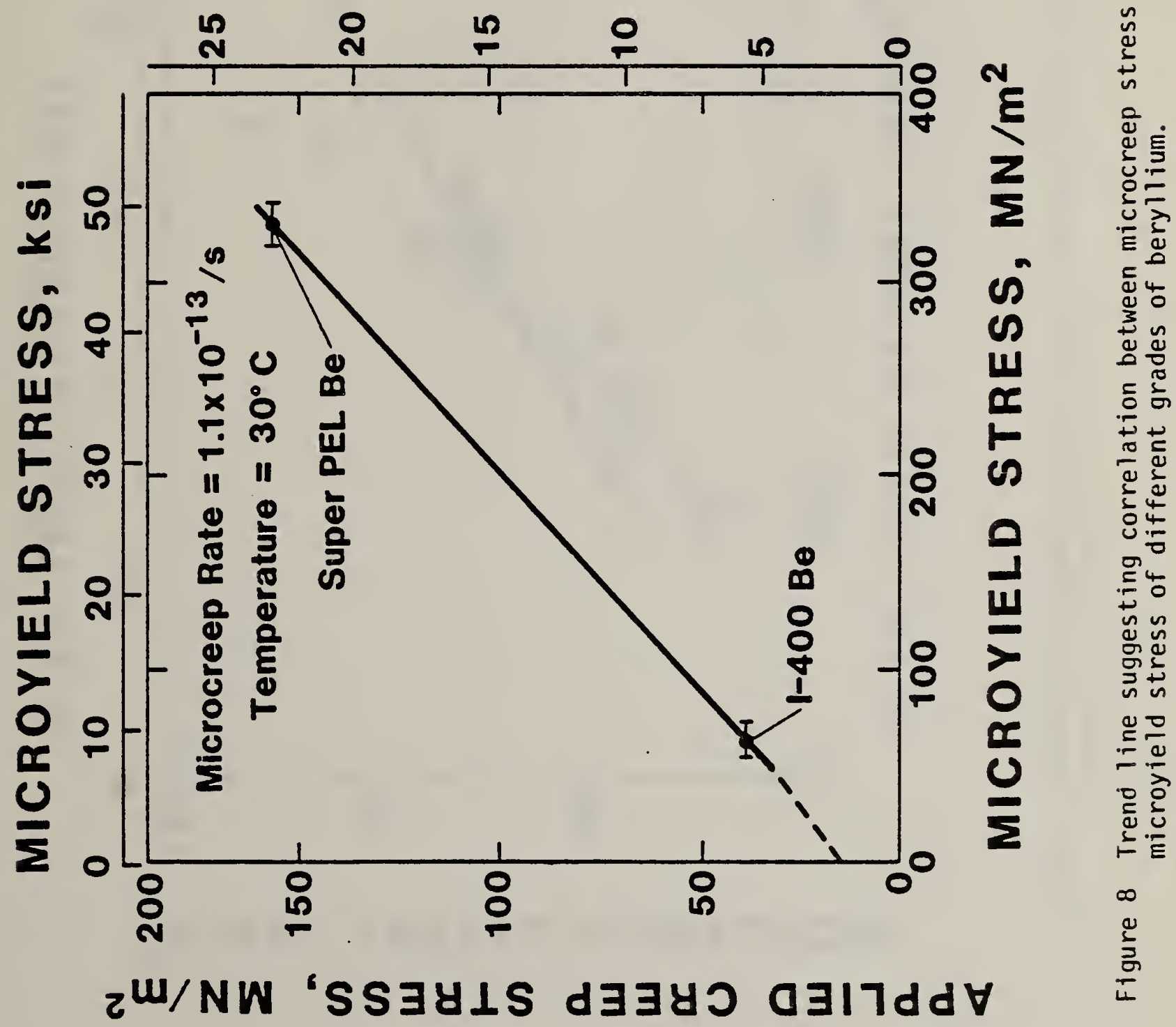




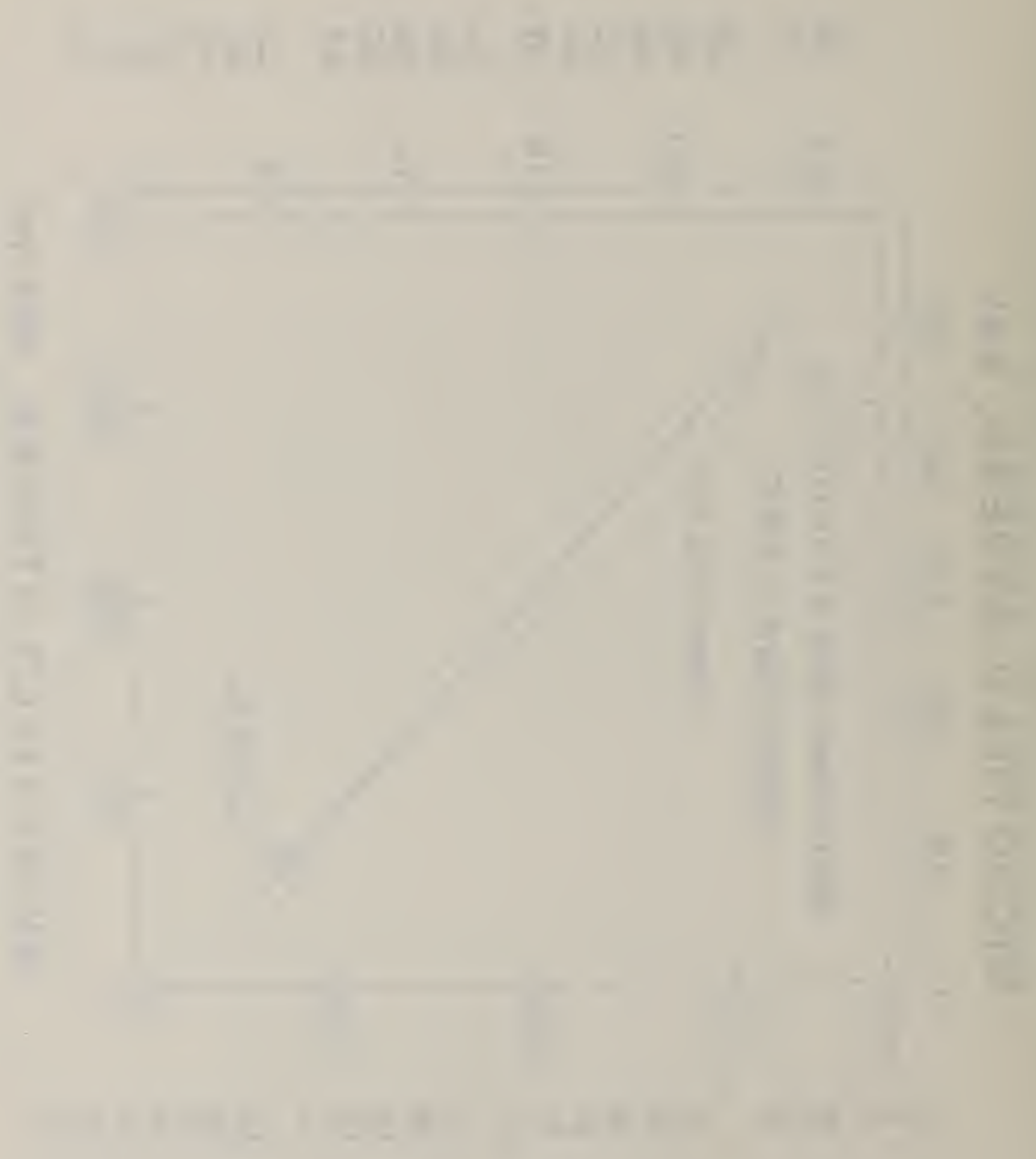




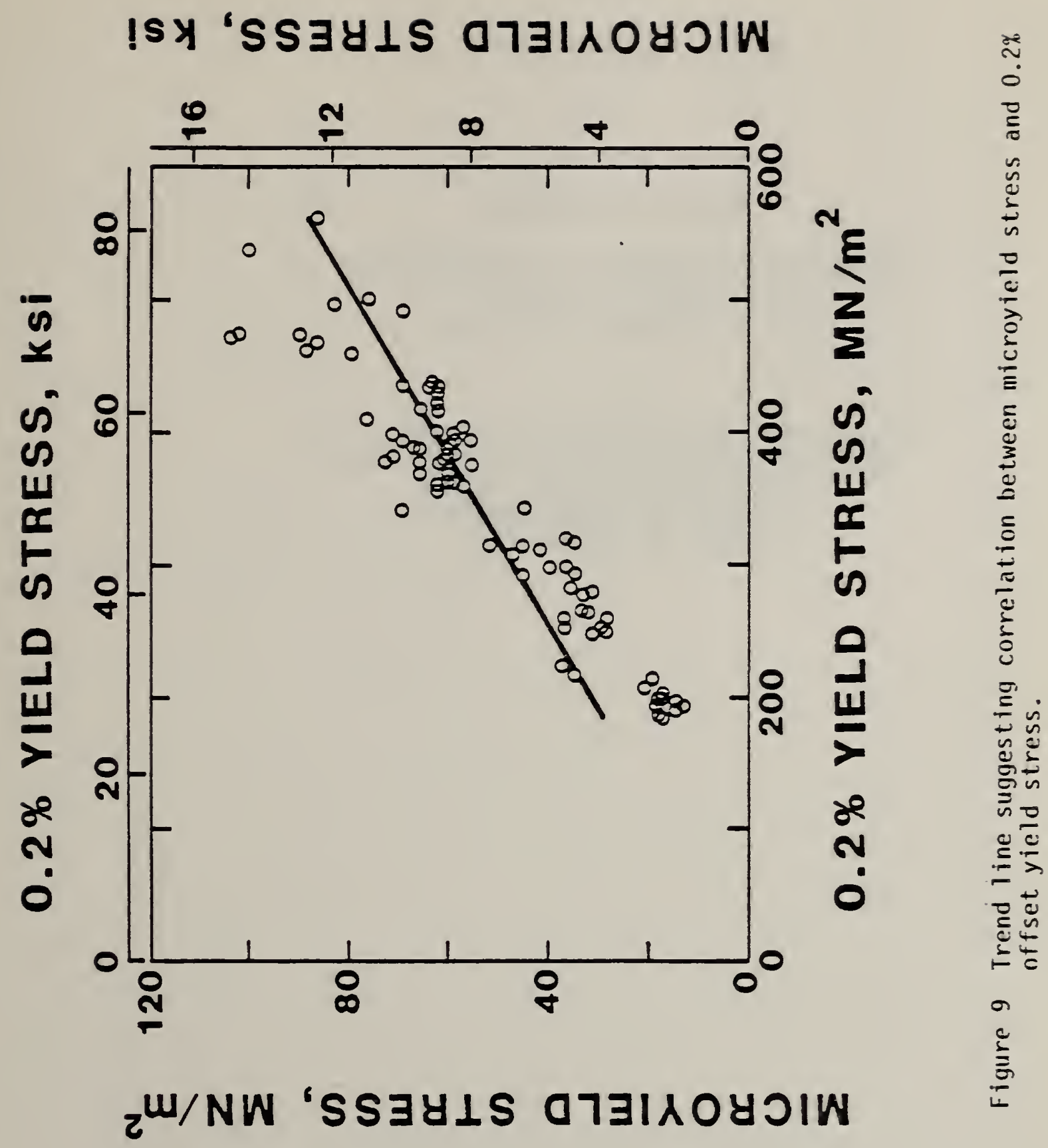




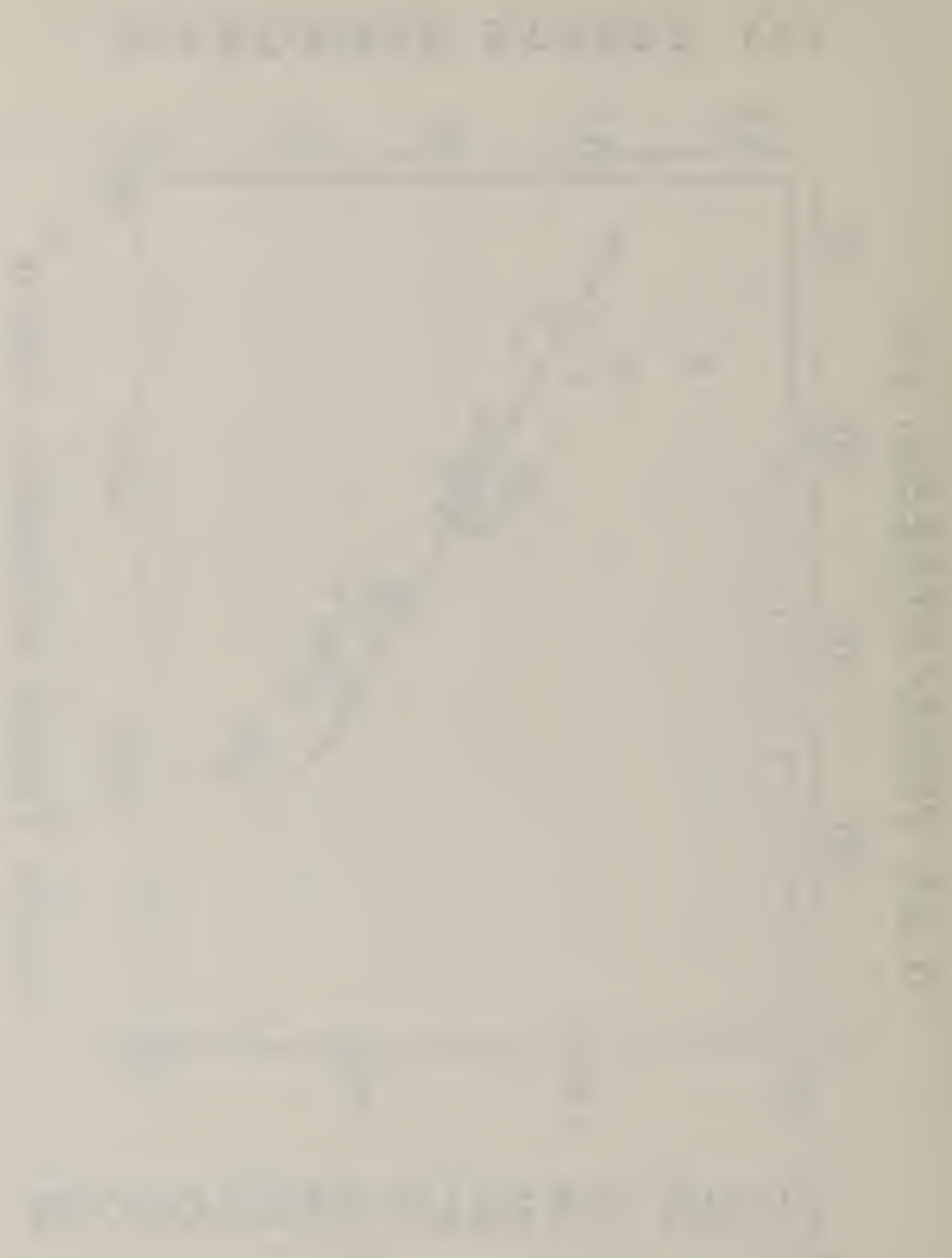




\section{PART B}

ANNUAL TECHNICAL REPORT

TO

OFFICE OF NAVAL RESEARCH

MATERIALS DIVISION

INSTRUMENTATION TO MEASURE MICROMECHANICAL

PROPERTIES OF BERYLLIUM

AND OTHER INSTRUMENT MATERIAL

BY

R. J. HOCKEN, B. BORCHARDT, AND TOM CHARLTON AUTOMATED PRODUCTION TECHNOLOGY DIVISION

CENTER FOR MATERIALS SCIENCE

NATIONAL BUREAU OF STANDARDS

WASHINGTON, DC 20234 


\section{PART 6 \\ INSTRUMENTATION TO MEASURE MICROMECHANICAL PROPERTIES OF BERYLLIUM AND OTHER INSTRUMENT MATERIALS \\ by}

R. J. Hocken and B. Borchardt

THE 1-D MICROCREEP A.PPARATUS

Since last year's report on the status of the 1-D microcreep apparatus, there has been considerable progress on solving its problems. The stability of the interferometer mount, a problem mentioned in last year's report, was carefully measured and solved by designing a new stable kinematic mount for the interferometer. This mount solidly attaches the interferometer optics to the same mounting plate used for the laser and detectors. The quarter wave plate was also re-mounted in an adjustable mount, and an improved quarter wave plate was purchased. The new quarter wave plate was larger in diameter to allow for a larger sample size.

We identified a problem with undesirable mechanical coupling from the outside shell of the thermostat to the sample positions. The outer shell rests on a rubber-o-ring, and can easily wander. If it firmly connected to the inside drum, the samples can be shifted relative to the interferometer. The solution eliminates the coupling by remachining the themostat insulator to give some clearance.

Another small source of noise was in the first stage amplifiers from the photomultipliers. New, better quality operational amplifiers cured this.

To improve the optics, we installed a spatial filter on the input side, allowing us to use the whole beam width again. We had been using only half of the width of the beam. The need to split the beam into two halves had come from the effect of a beam returning into the laser. In effect, this makes the laser cavity look like a different length and interferes very strongly with the wavelength control. The spatial filter keeps the returning beam from passing through, since it is very sensitive to alignent with the optics. The filter incorporated a beam expander, so the laser could illuminate larger samples. The mechanics of the thermostat chamber were modified to allow larger samples: a size of 0.4375 inches $0 . D$. and 0.250 ID was settled on. Larger samples were necessary to improve the optical quality of the signals at the detectors. The 0.083 inch holes we tried first had effectively no area left which was not affected by diffraction effects. With a 0.250 hole, the central area of interest is undisturbed. This larger size quadrupled the area of the inside section of the pattern, and tripled the area of the outer ring. The increase in cross-sectional area changed the load limits of the apparatus (as measured in PSI); the minimum on the loadable samples is now 67 PSI, and the maximum is about 4000 PSI.

Because of their ready availability, invar samples were obtained in the proper diameter. After overcoming some mechanical difficulties with the large sample size and with obtaining good quality "button" reflectors for the bottoms of the samples, a stability test was taken. The test showed a large improvement over previous runs in the noise, to a level of about $2 \times 10-8$ for short term, 

and $5 \times 10-8$ for long tern intercomarisons. These numbers are for the samples which were most nearly parallel; the worst samples are 3 or 4 times as bad. The non-parallelism affects noise by introducing a dependence on cross travel; the apparatus as designed cannot hold horizontal position perfectly. Thus, the effective length changes as the interferozeter zoves to a thicker or a thinner part of the sample.

For the first time, repeated comparison measurements were taken between different samples over an extended period of time. This procedure gave the repeatabilities cited above. This was the original intent of the systen's design, firally realized.

At this low noise level, a snall drift was detected in the interferometer output. This was diagnosed as due to a leak in the pressure vessel, wich allowed helium and air to mix, slowly changing the index of refraction. This problem was solved by pumping continually and taking data at a pressure of less than 20 microns of mercury. 100 microns $(0.1 \mathrm{~m}$ ) is the resolution of the barometer; thus the error is less than 3 parts in $10^{\circ}$ at this pressure. In the course of these investigations, a measurement of the index of zefraction of helium was coincidentally made, giving a number in agreenent with the accepted value. This gave us further confidence in the apparatus.

The most significant test was a long term run on the invar samples. The results obtained are based on a Iun of 1500 hours (approximately two porshs) during which a vacuum was continually maintained (about 15 millitor at the pump) and the temperature was controlled within about $8 \mathrm{mi}$. The pressure occasionally was raised to about 200 torr of helium for testing. There was occasional excursions of about $1 \mathrm{C}$ when our building air conditioning failed, exceeding the capacity of the apparatus thermal system to maintain control; the data obtained during these times were not included. The return to control temperature, $20.98 \mathrm{C}$, was verified by a platimun resistance thermometer. The stress was constant at 67 PSI in tension for Invar 2, 3, and 4. Invar 1, steel and Cervit were stressed only by their own weigit.

The basic results are shown in the attached figures. Note that the vertical scale is relative phase; this means that a different constant shift has bee: added to the data for each sample to separate them vertically on the grapi. The uncertainty brackets represent the short term noise as recorded on the chart recorder during each data collection period. These periods were normally 1 or 2 hours, except overnight and during weekends. The shorter time bases of 2,3 , and 4 reflect the fact that the alignment of each sample with the interferometer system was occasionally adjusted and only phase values which were obtained while the system could be shown to be working were retained. Proof of functioning was considered to be shown by the proper response to a brief ( 5 minute) injection of pure helium into the system. Since the index of refraction is increased temporarily, the optical path length as measured by the interferometer should increase in a linear manner. If the interferometer is not properly aligned for a particular sample, the pressure response becomes 

nonlinear or, in the worst case, nonexistent. Thus, we have confidence that all of the points shown on the graph are real and significant.

The least squares slopes are as follows:

$$
\begin{array}{lcc}
\text { sample } 1 & 5.8 \pm 0.6 & \text { nano strains/day } \\
\text { sample } 2 & 9.3 \pm 1.9 & " \\
\text { sample } 3 & 14.1 \pm 0.9 & " \\
\text { sample } 4 & 13.9 \pm 1.4 & "
\end{array}
$$

The uncertainties are one standard deviation. The data are differenced point by point from the average of cervit and steel. Figure 2 shows the same data plotted without differencing from the steel and cervit sample.

The least squares slopes are:

$\begin{array}{lcc}\text { sample } 1 & -2.3 \pm 0.5 & \text { nano strains/day } \\ \text { sample } 2 & +0.5 \pm 1.1 & " \\ \text { sample } 3 & +5.7 \pm 1.1 & " \\ \text { sample } 4 & +8.3 \pm 1.5 & " \\ \text { cervit } & -7.7 \pm 0.4 & " \\ \text { steel } & -8.0 \pm 0.3 & \end{array}$

We cannot say unambiguously whether the drift of the standard samples is in the sample or fin the instrument. These rates are significantly larger than previous results on gage block instability. However, these blocks are not typical gage blocks in that both have recently had a hole drilled down the center, which could release residual stresses and cause instability. Hence, the rates we see are not outside the bound of possibility. In addition to instability due to recent machining, other phenomena include a change in the wringing film between the sample and its platen, laser instability (although this is unlikely), and differential deposition of surface films on the sample and platen. Subtraction of the slope of the standards may or may not be the correct approach. It is our judgement, particularly in view of the fact that the two standards are changing together, that what we see is really instrumental drift from some as yet unknown cause. 



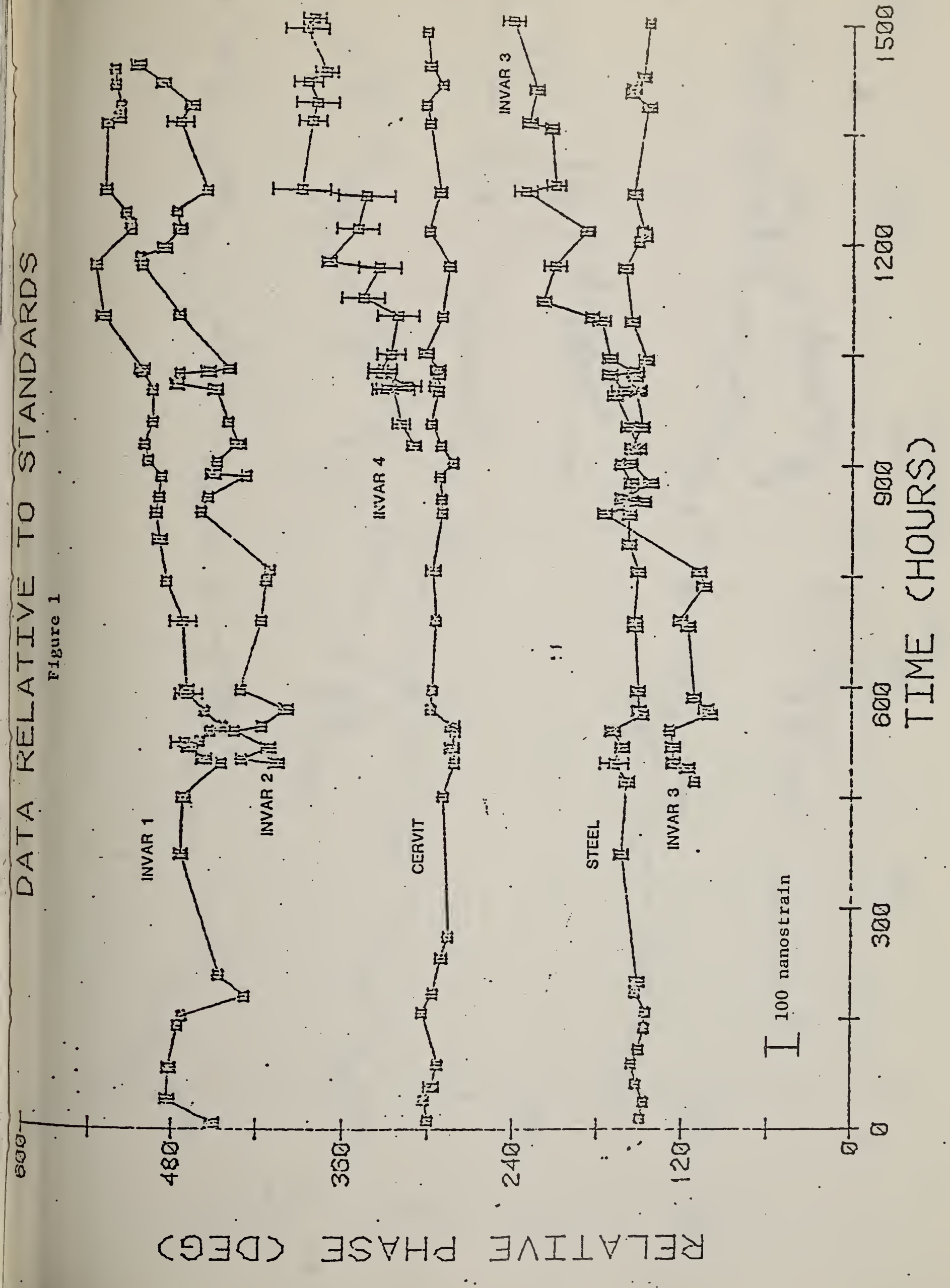




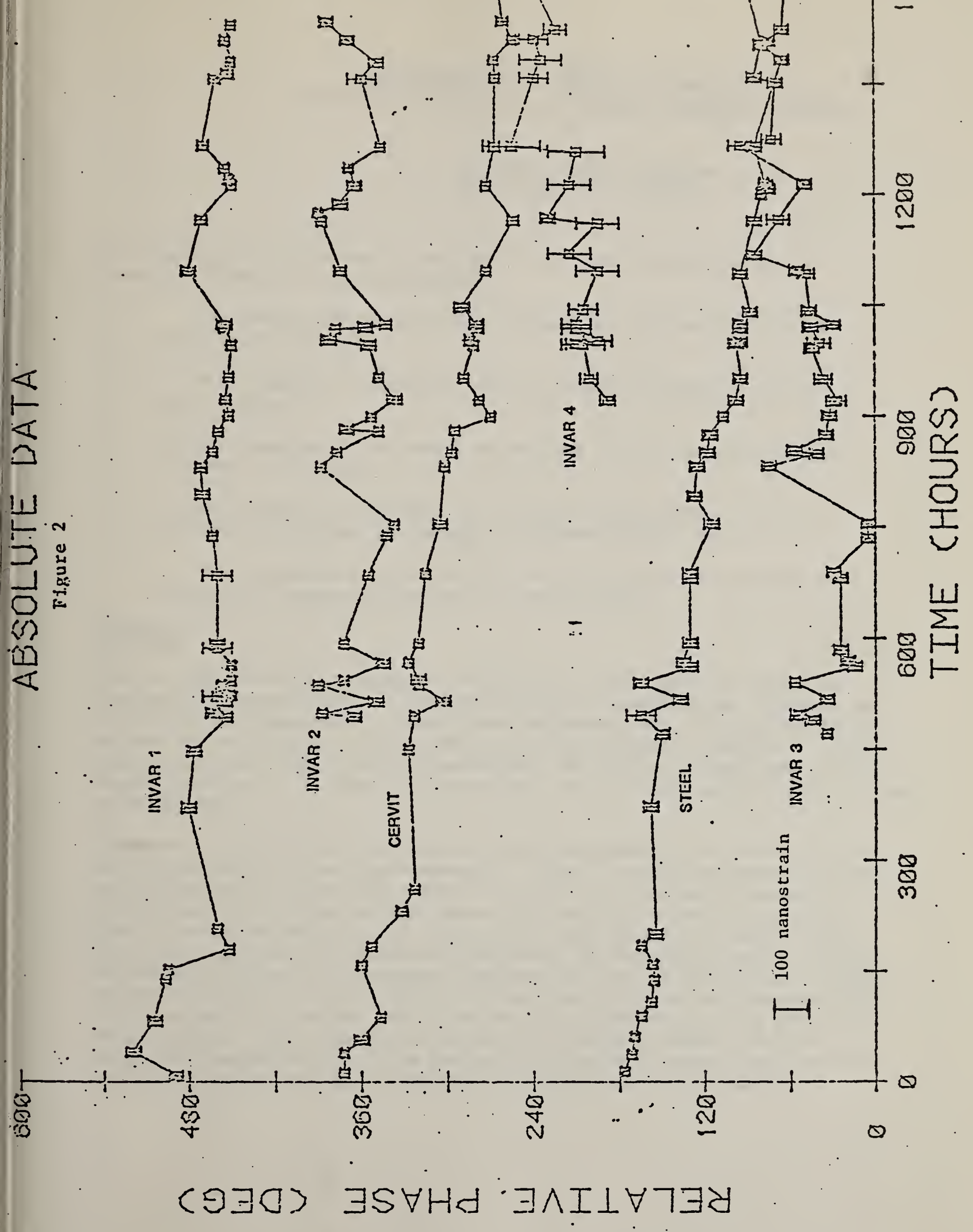



\section{PART B \\ INSTRUMENTATION TO MEASURE MICROMECHANICAL PROPERTIES OF BERYLLIUM AND OTHER. INSTRUMENT MATERIALS by \\ R. J. Hocken and T. Charlton BIAXIAL TESTING SYSTEM}

The highlights of this year's progress on the study of microcreep in biaxially stressed beryllium include;

a) completion of load fram hardware with photographic data acquisition system.

b) extensive testing of entire hardware system with steel dummy samples.

c) loading of two beryllium samples with collections of over 300 data photographs.

d) further development of the image analysis/data reduction software with extensive testing and improved modularity.

e) preparation of a review report for reference purposes on the biaxial testing system for the project files.

\section{HARDWARE}

The six load frame/interferometer stations were completed and assembled. A large effort was invested in developing adequate assembly and alignment techniques for the frame structure and interferometer mount since the uniformity of the loading process was presumed to be very important. Without a uniform repeatable process for loading the samples, the stress distribution in the sample could not be reliably calculated for use in the simulation calculations of Draper Labs.

Three major improvements were made in the frame design as a result of our experience with the load frame assembly. First, a centering guide was added to the underside of the sample mount. This addition proved necessary for the satisfactory positioning of the contact ball at the center of the sample disk. The second addition was a thin guide ring around the sample. This guide ring was needed to constrain the travel of the sample during loading to prevent tilting, and thus poor centering for the circumferential loading against the steel reference flat. The third modification was the addition of the access ports in the load frame to allow inspection of the guide ring after loading. These inspection points were needed to assure that the sample was completely free from the guide ring after loading was complete, so there is no possibility of unknown lateral stress on the sample. 



\section{TESTING}

To assure successful operation of the entire hardware system with the first beryllium sample, extensive testing of the system was done using a relatively inexpensive "dummy" steel sample. The first trial loadings and interferometer adjustments quickly led to a new design for the optical flat adjustable mount. Following this improvement, the steel sample was repeatedly loaded until the techniques were adequate to provide satisfactory, reproducible interference pattern.

Next, the photographic data system was tested and fine tuned. A series of test photographs were made to provide data for selection and aperture and exposure time. Since one of the important requirements of the system is the ability to traverse from one sample station to another, we tested our ability to travel away from and back to the station with the steel sample in it. This system seems to work very well, but depends strongly upon proper, careful initial alignment of the load frames.

After the first beryllium sample was loaded, the testing of this system continued. We repeatedly traversed between the steel sample and the beryllium sample over an extended period of time without major difficulty.

\section{SAMPLES}

Two beryllium samples have now been loaded. The first had a dead weight of 3 kilograms, and the second load was 10 kilograms. Over 300 data photographs have been taken of the changing interference pattern since the first sample was loaded. We have established our own in-house capability to do the photographic processing work to be certain that no data is lost.

The only problems that have been encountered in the data collection are failures of the room temperature control. Sudden temperature shifts apparentIy introduce a change in the optical wedge angle, which causes a major change in the interference pattern. However, the steel reference flat directly measures this change, so it is not of major concern. (Such possible changes were the reason for originally including the reference flat in the design.)

\section{SOFTWARE}

Software development and testing has continued. It has continued to be hampered by limited access time on the image analysis system. The original software has been considerably improved by structuring the code more strongly, modularizing its function, and incorporating a good deal of fault tolerance. 


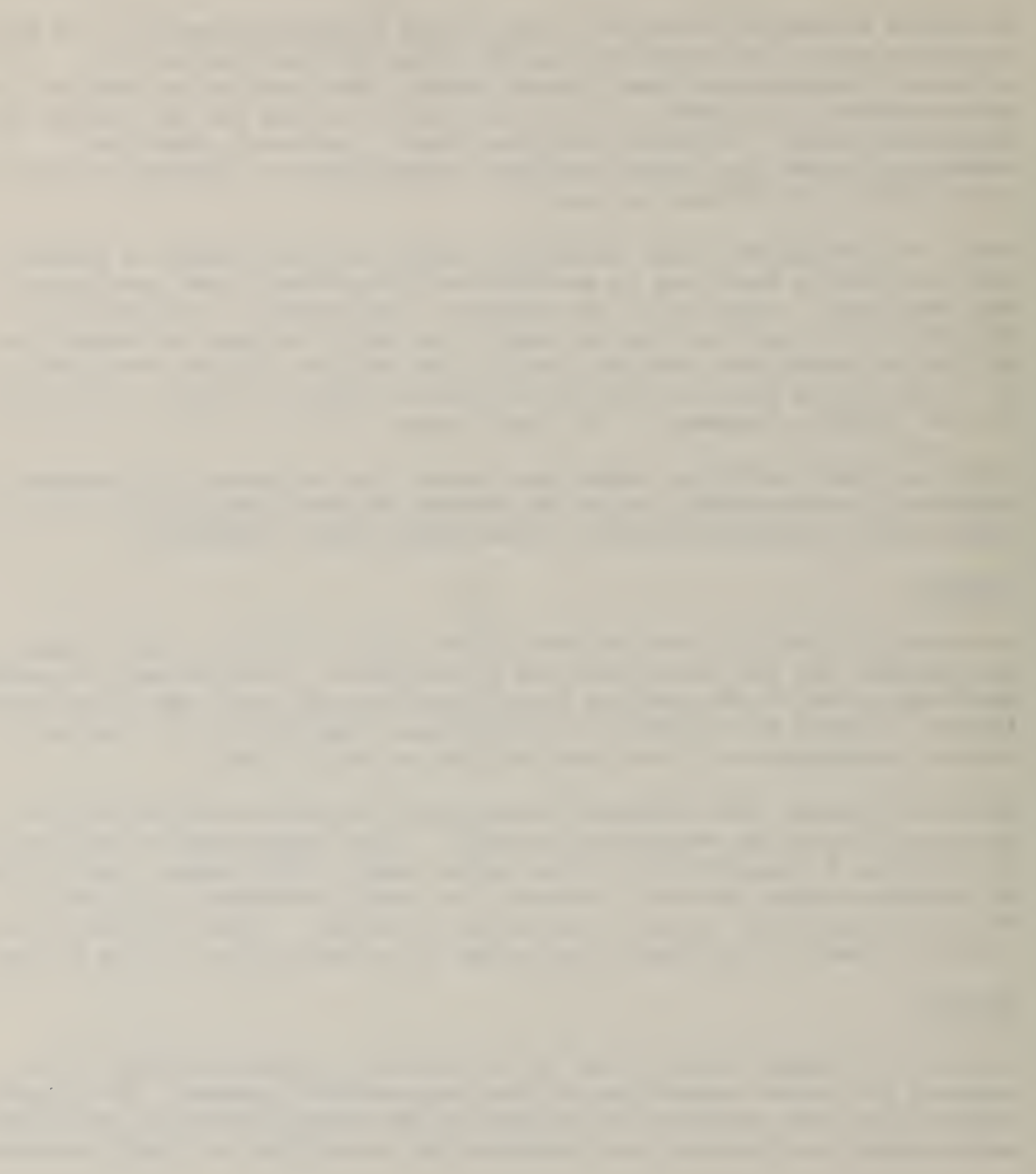


The necessary analysis software unfortunately exceeded the memory capacity of the image analysis computer in August 1981. While this is not a major problem, it has led to a major delay. the likelihood of this was foreseen at the beginning of the software development, thus leading us to write the programs in a modular form. It would then be possible to segment the code into several smaller sequential programs, each of which required much less memory capacity. This segmentation is straightforward but labor intensive.

The image analysis facility was planned to have a new computer installed in September with improved speed and more memory. We decided to delay segmentation since the effort would probably be obsolete before it was completed. However, the installation of the new computer has been pushed back by a month every month since September, and we are still waiting. If it is not available by February, we will proceed with program segmentation regardless of March promises.

\section{REPORT}

A review report on the biaxial system was prepared early in the year for archival purposes. It briefly reviewed the details of the project requirements, hardware design to data, software approach, and functional overview of the entire data acquisition and processing system.

1. T. Charlton and R. Hocken: Review of Biaxial Beryllium Microcreep Test System: Status Report, December, 1980. 

PART B

APPENDIX I - SPECIMEN INVENTORY

MICROMECHANICAL PROPERTIES OF BERYLLIUM

AND OTHER INSTRUMENT MATERIALS

\begin{tabular}{|c|c|c|c|c|}
\hline \multirow{2}{*}{$\begin{array}{l}\text { TESTING } \\
\text { SYSTEM } \\
\end{array}$} & \multicolumn{2}{|c|}{ SPECIMEN DESCRIPTION } & \multirow{2}{*}{ MATERIAL } & \multirow{2}{*}{ QUANTITY } \\
\hline & SHAPE & SIZE & & \\
\hline \multirow[t]{5}{*}{$\begin{array}{l}\text { One- } \\
\text { Dimension }\end{array}$} & \multirow{3}{*}{$\begin{array}{l}\text { Hollow } \\
\text { Cylinder }\end{array}$} & $\begin{array}{l}4-\text { in. long } \\
0.400 \text { - in. diam. } \\
0.25 \text { - in. bore. }\end{array}$ & $\begin{array}{l}\text { I-400 } \\
\text { beryllium }\end{array}$ & 1 ready for testi \\
\hline & & \multirow[t]{2}{*}{$\begin{array}{l}4 \text { - in. long } \\
7 / 16 \text { in. outside diam. } \\
0.25 \text { - in. bore. }\end{array}$} & INVAR & 4 in test \\
\hline & & & $\begin{array}{l}\text { I- } 400 \\
\text { bery } 11 \text { ium }\end{array}$ & 4 ready for testi \\
\hline & $\begin{array}{l}\text { Hollow } \\
\text { Cylinder }\end{array}$ & $\begin{array}{l}4-\text { in. long } \\
0.9 \text { - in. diam. } \\
0.25 \text { - in. bore. }\end{array}$ & $\begin{array}{l}\text { Steel Gage Block } \\
\text { Standard }\end{array}$ & 1 in test \\
\hline & $\begin{array}{l}\text { Square } \\
\text { Parallel- } \\
\text { Apiped }\end{array}$ & $\begin{array}{l}4 \text { - in. long } \\
1-\text { in. square section } \\
0.25 \text { - in. bore }\end{array}$ & Cervit Standard & 1 in test \\
\hline Biaxial & Disk & $\begin{array}{l}2 \text { - in. diam. } \\
1 / 8 \text { - in. thick }\end{array}$ & $\begin{array}{l}\text { I }-400 \\
\text { bery } 11 \text { ium }\end{array}$ & $\begin{array}{l}2 \text { in test } \\
2 \text { on hand } \\
2 \text { in preparation } \\
\text { at C. S. Draper L } \\
\text { Cambridge, MA. }\end{array}$ \\
\hline
\end{tabular}




